\title{
A numerical model to simulate ductile tearing-creep crack growth interaction
}

DOI:

10.1016/j.ijpvp.2019.103920

\section{Document Version}

Accepted author manuscript

Link to publication record in Manchester Research Explorer

\section{Citation for published version (APA):}

Ainsworth, R., Oh, Y-R., Kim, S-J., Kim, Y-J., \& Nikon, K. (2019). A numerical model to simulate ductile tearingcreep crack growth interaction. International Journal of Pressure Vessels and Piping.

https://doi.org/10.1016/j.ijpvp.2019.103920

\section{Published in:}

International Journal of Pressure Vessels and Piping

\section{Citing this paper}

Please note that where the full-text provided on Manchester Research Explorer is the Author Accepted Manuscript or Proof version this may differ from the final Published version. If citing, it is advised that you check and use the publisher's definitive version.

\section{General rights}

Copyright and moral rights for the publications made accessible in the Research Explorer are retained by the authors and/or other copyright owners and it is a condition of accessing publications that users recognise and abide by the legal requirements associated with these rights.

\section{Takedown policy}

If you believe that this document breaches copyright please refer to the University of Manchester's Takedown Procedures [http://man.ac.uk/04Y6Bo] or contact uml.scholarlycommunications@manchester.ac.uk providing relevant details, so we can investigate your claim.

\section{OPEN ACCESS}




\title{
A NUMERICAL MODEL \\ TO SIMULATE DUCTILE TEARING- CREEP CRACK GROWTH INTERACTION
}

Young-Ryun Oh, Seung-Jae Kim, Yun-Jae Kim* Korea University, Department of Mechanical Engineering Anam-Dong, Seongbuk-Ku, Seoul 136-701, Korea

\section{Robert A Ainsworth}

School of Mechanical, Aerospace \& Civil Engineering The University of Manchester, Manchester M13 9PL, UK

\author{
Kamran Nikbin \\ Department of Mechanical Engineering \\ Imperial College London, South Kensington Campus, \\ London SW7 2AZ, UK
}

* Corresponding author

8? $+82-2-3290-3372$

(Fax) +82-2-926-9290

(E-Mail) kimy0308@korea.ac.kr

Manuscript for Submission to International Journal of Pressure Vessels and Piping (SMiRT 24 Special Issue)

Submission Date: August 2018

1st Revision: April 2019

2nd Revision: June 2019 


\begin{abstract}
Ductile tearing and creep crack growth are generally treated independently but there are situations in which they can occur simultaneously. First, creep crack growth calculations in components are often continued to large defect sizes in order to determine when limiting conditions for short-term fracture are reached. Secondly, in order to obtain data in reasonable timescales, experimental creep crack growth tests are often performed at high loads such that plasticity occurs in the tests, particularly as the crack grows to larger sizes. This paper presents a numerical model to simulate the interaction of ductile tearing and creep crack growth to address such cases. A strain-based damage model is introduced with total damage assumed to be the linear summation of creep and plastic damage. The model is applied to Type $316 \mathrm{H}$ stainless steel at $550{ }^{\circ} \mathrm{C}$ with the parameters in the damage model determined from tensile, creep and fracture toughness test data. Predictions using the proposed model are then compared with notched creep tensile and creep crack growth test results and shown to be in good agreement with experimental measurements of creep deformation and crack growth.
\end{abstract}

\title{
Keywords:
}

Creep damage, Creep crack growth, Plastic damage, Ductility damage model, Strain rate effect

\section{NOMENCLATURE}

$\begin{array}{ll}a & \text { crack length } \\ C, k & \text { material constants in modified Cocks and Ashby model, see Eq. (12) } \\ m & \text { material constant for tertiary creep strain, see Eq. (14) } \\ n & \text { creep exponent } \\ P, P_{0} & \text { applied load and limit load, respectively } \\ R & \text { notch radius } \\ \alpha, \beta & \text { material constants in modified Rice \& Tracey model, see Eq. (9) } \\ \Delta a_{c r}, \Delta a_{p l} & \text { creep crack growth amount and ductile tearing amount, respectively } \\ \Delta \varepsilon_{c r}, \Delta \varepsilon_{p l} & \text { incremental creep and plastic strain, respectively } \\ \Delta \omega_{c r}, \Delta \omega_{p l} & \text { incremental creep and plastic damage, respectively } \\ \varepsilon_{f},{ }^{*}{ }_{c r}, \varepsilon_{f},{ }^{u} p l & \text { uni-axial creep and plastic ductility, respectively } \\ \varepsilon_{f,}{ }^{*}{ }^{c}, \varepsilon_{f},{ }^{*} p l & \text { multi-axial creep and plastic ductility, respectively } \\ \dot{\varepsilon}_{c r}, \dot{\varepsilon}_{p l} & \text { equivalent creep and plastic strain rate, respectively } \\ \dot{\varepsilon}_{c r}^{p}, \dot{\varepsilon}_{c r}^{s}, \dot{\varepsilon}_{c r}^{\omega} & \text { primary, secondary and tertiary creep strain rate, respectively } \\ \sigma_{n e t} & \text { net section stress } \\ \sigma_{0} & \text { yield stress } \\ \sigma_{1} & \text { maximum principal stress } \\ \sigma_{e} & \text { equivalent stress } \\ \sigma_{m} & \text { mean normal stress } \\ \omega_{c} & \text { critical plastic damage } \\ & \end{array}$




$\begin{array}{ll}\text { Abbreviations } & \\ \text { 3-D } & \text { Three-dimensional } \\ \text { C\&A } & \text { referring to the Cocks and Ashby model } \\ \text { FE } & \text { finite element } \\ \text { MDF }_{c}, M_{p} & \text { creep and plastic multi-axial ductility factor, respectively } \\ \text { R\&T } & \text { referring to the Rice and Tracey model } \\ \text { S } & \text { referring to the Spindler model } \\ \text { W\&T } & \text { referring to the Wen and Tu model }\end{array}$

\section{INTRODUCTION}

Fitness-for-service assessments of cracked components operating at both high and low temperatures are important in the power-generation and other industries. To support such assessments, fracture toughness and creep crack growth tests on various geometries of laboratory specimen are routinely performed and numerical modelling techniques to predict creep crack growth have been developed, as summarised below.

Techniques to simulate creep damage evolution and subsequent creep rupture using stress-based damage models have been developed, for example, by Hayhurst and co-workers [15] and Hyde and co-workers [6]. When combined with a technique to simulate the loss of loadcarrying capacity when the damage level becomes critical, these methods can also be used to simulate creep crack growth. Thus, Yatomi and co-workers [7-10] used the Cocks and Ashby multi-axial ductility model [11] for damage and a node release technique to simulate crack growth. Wen and co-workers [12-15] also presented a technique using various multi-axial ductility models. The present authors extended Yatomi's approach [16, 17] but alternative techniques to model creep behaviour and crack growth were employed. Three-dimensional (3D) finite element (FE) damage analyses were used to simulate creep crack growth testing and comparisons with experimental creep crack growth rate data from various fracture mechanics geometries showed good agreement [17].

In all the above models, only creep damage was accounted for to simulate creep crack growth. However, as noted by Ainsworth and Booth [18], to assess margins for a cracked component under fault loading conditions at high temperatures, assessed load levels or defect sizes may be sufficiently high for ductile tearing to occur and thus for crack growth to occur by the interaction of ductile tearing and creep crack growth. They also noted that, in typical shortterm creep crack growth testing of stainless steels, sustained load levels are often such that plasticity effect are not negligible. Therefore, there are situations where it is necessary to consider the interaction of ductile tearing and creep crack growth, and existing damage models are inadequate. 
This paper seeks to address this gap by proposing a numerical, combined plastic and creep damage model to simulate crack growth by tearing-creep interaction. Section 2 of this paper first describes the experimental data used to provide inputs to the modelling and the experimental data used for verification. From examination of these experimental data and from preliminary analyses, it transpires that there are three important issues, which need to be addressed within the modelling. The first is that there is an effect of strain rate on material ductility, as described in Section 2. Secondly, it is necessary to incorporate plastic damage within the creep crack growth simulation; the combined damage model to cover this is described in Section 3. Thirdly, there is a major effect of multiaxial stress on both plastic and creep damage, as observed in previous modelling studies. To address this for plasticity a model used previously is briefly described in Section 3; for the creep damage part of the model, a modified Cocks \& Ashby model is proposed and this is also briefly described in Section 3. Results from the model and comparisons with experimental data are discussed in Section 4 before Section 5 concludes the present work.

\section{SUMMARY OF MATERIAL AND MECHANICAL TEST DATA}

To develop a numerical model to simulate tearing-creep interaction in this paper, a set of mechanical test data were considered [19]. The material considered is Type $316 \mathrm{H}$ stainless steel. Specimens for tensile and creep tests were extracted from an ex-service superheater header.

\subsection{Uniaxial Tensile Data}

The true stress-strain curve from an uniaxial tensile test at $550{ }^{\circ} \mathrm{C}$, from [20], is shown in Fig. 1. The yield and tensile strengths are $170 \mathrm{MPa}$ and $588 \mathrm{MPa}$, respectively. These data are used as input to FE damage analyses.

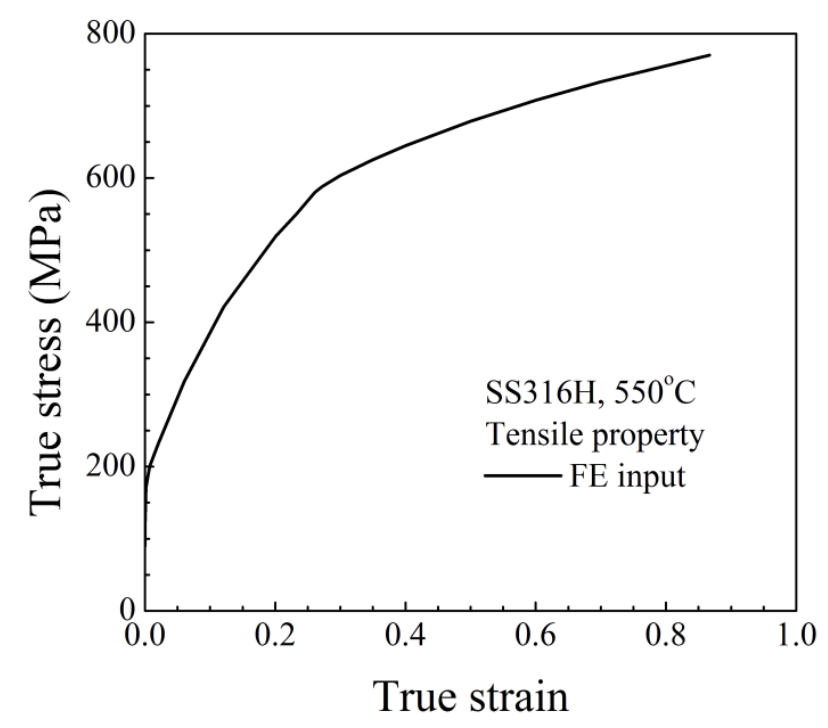

Fig. 1. True stress-strain curve of Type $316 \mathrm{H}$ stainless steel at $550{ }^{\circ} \mathrm{C}$ 


\subsection{Smooth Bar Creep Test Data}

Creep tensile tests using the smooth specimens depicted in Fig. 2(a) were performed at $550{ }^{\circ} \mathrm{C}$ [19]. Tests were performed at five sustained nominal stress levels (290 to $366 \mathrm{MPa}$ ). The resulting variations of creep strain with time are reproduced in Fig. 3, where the initial elastic-plastic loading strain has been removed from the total deformation. The average elongation at failure was found to be $\sim 7.06 \%$ and the average true fracture strain estimated from the reduction of area was $\sim 21.4 \%$. Note, FE simulations of these tests, shown in Fig. 3, are discussed later.

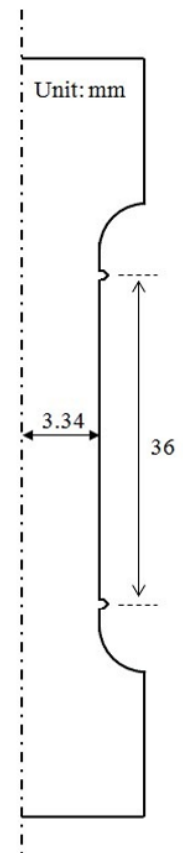

(a)
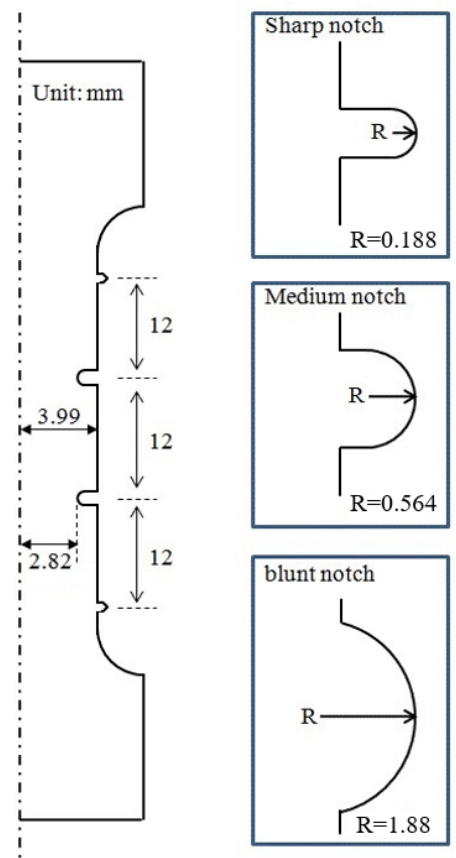

(b)

Fig. 2. Geometries and dimensions of (a) smooth and (b) notched creep tensile test specimens (units: $\mathrm{mm}$ ).

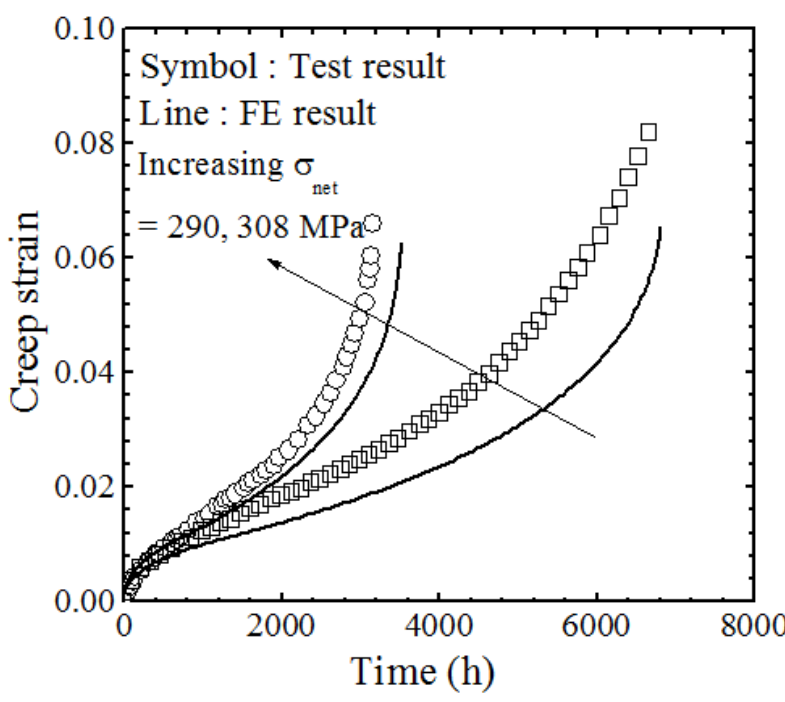

(a)

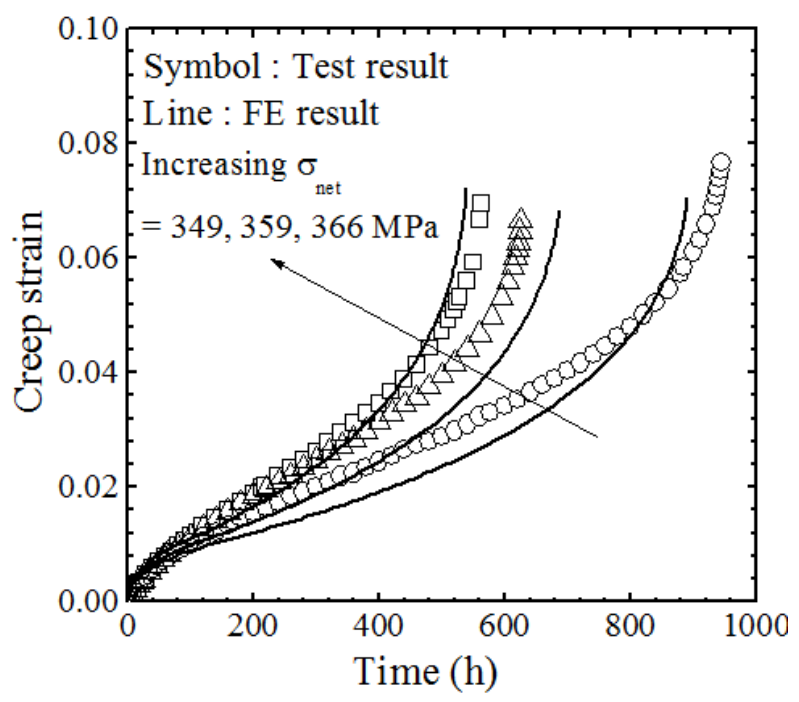

(b) 
Fig. 3. Smooth bar creep tests: (a) low stress levels and (b) high stress levels. Figures include comparison with FE simulation results which will be discussed later in Section 3.4.

\subsection{Strain Rate Effects on Uniaxial Ductility}

It is well known that creep ductility depends on test duration. This can be described as an effect of time, stress or strain rate in the test. For example, Spindler et al. [21] presented data as an effect of strain rate on uniaxial creep ductility for Type $316 \mathrm{H}$ steels at temperatures in the range 500 to $600{ }^{\circ} \mathrm{C}$ and results from [21] are reproduced in Fig. 4(a). The lower bound value of long-term creep ductility was 0.07 , consistent with the current data shown in Fig. 3 . The short-term ductility at high strain rates was 0.62 , more consistent with the uniaxial ductility in the tensile test shown in Fig. 1. The effect of strain rate was attributed to a change in mechanism and a linear transition was used to describe behaviour between the long-term and short-term values on the log-log plot of Fig. 4(a) [21]. The data in Fig. 4(a) have been fitted by

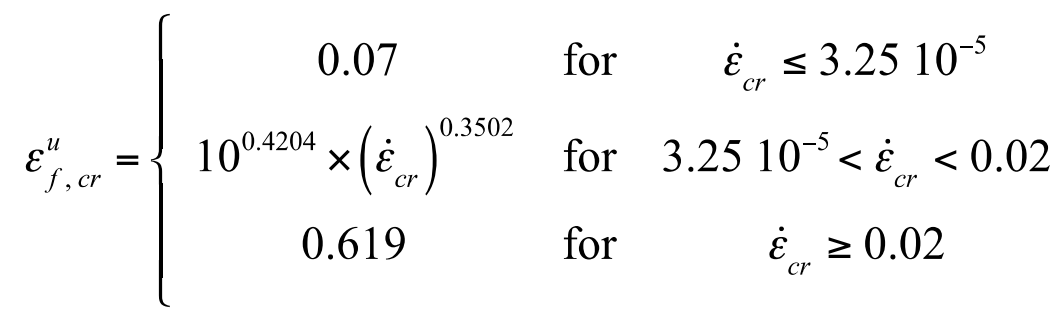

where $\varepsilon_{f, c r}^{u}$ is the uniaxial creep ductility and $\dot{\varepsilon}_{c r}$ is equivalent creep strain rate.

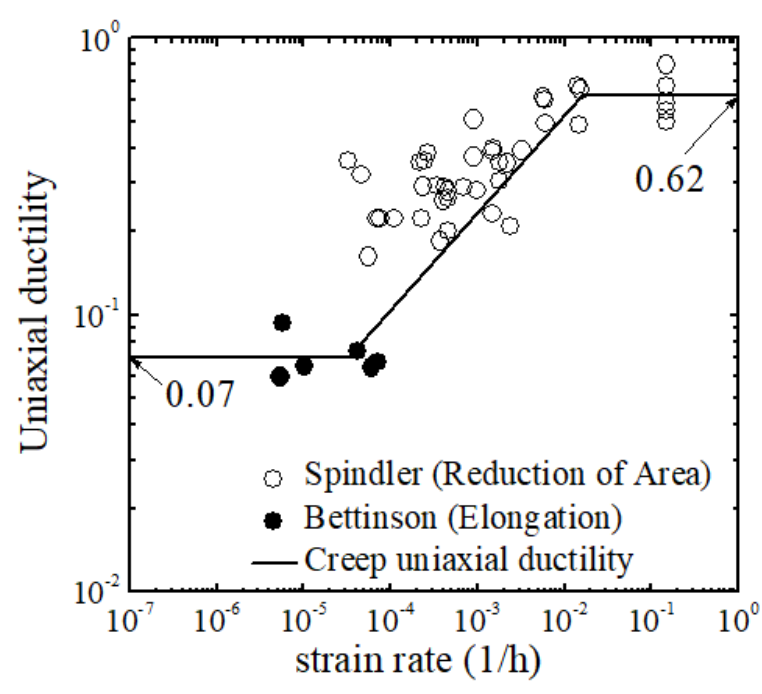

(a)

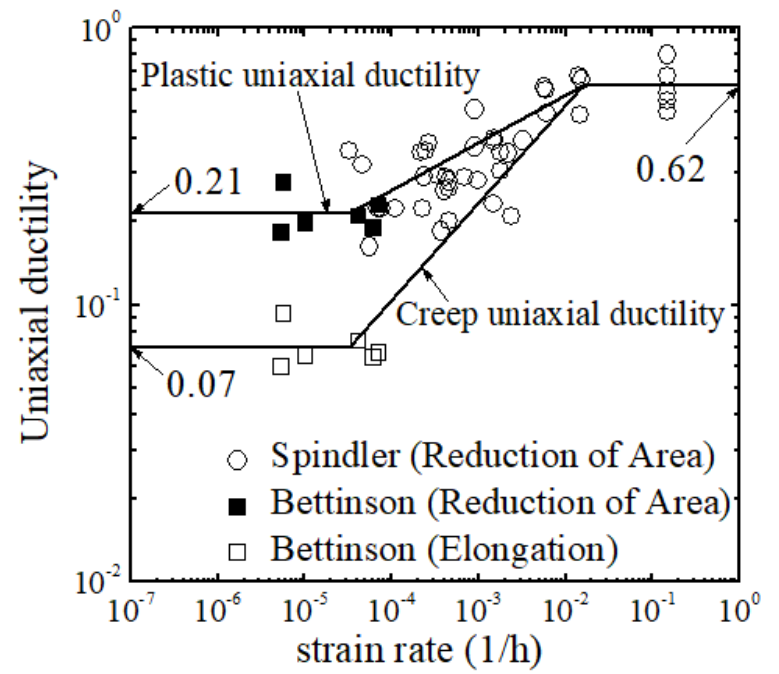

(b)

Fig. 4. (a) Variation of uni-axial creep ductility with strain rate for $316 \mathrm{H}$ stainless steel, reproduced from Ref. [19, 21], and (b) variations of uni-axial creep and plastic ductility.

On initial loading of a test specimen or component at high temperature, the elasticplastic uniaxial ductility is described by the data in Fig. 1 obtained from tests at conventional strain rates. However, as crack growth proceeds, additional plastic strains occur at strain rates 
comparable to the creep strain rates. Thus, plastic straining occurs at much lower strain rates than in conventional tensile testing. As with the data in Fig. 4(a), the corresponding ductility is expected to be dependent on the strain rate, reducing at lower strain rates. Here, it is assumed that the plastic uniaxial ductility can be obtained from the reduction of area data, shown in Fig. 4(a). The value at low strain rates is $21 \%$ whereas, at high strain rates, it is assumed that the ductility is consistent with the creep ductility of Eq. (1). The strain rate dependence is assumed to be given by

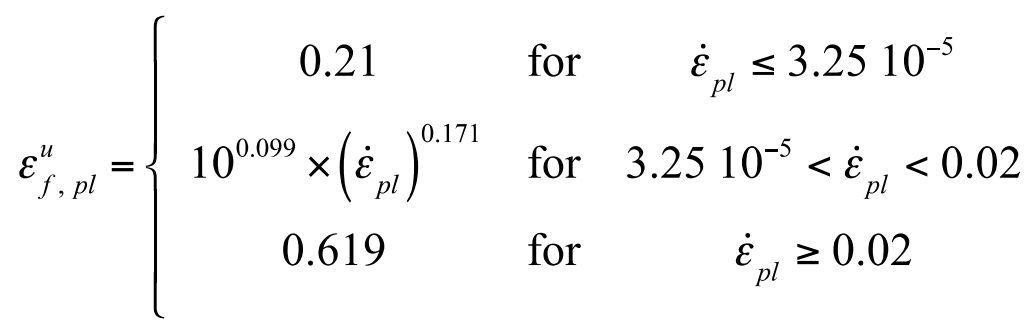

where $\varepsilon_{f, p l}^{u}$ is the uniaxial plastic ductility and $\dot{\varepsilon}_{p l}$ is equivalent plastic strain rate. This is shown in Fig. 4(b).

\subsection{Notched Bar Creep Test Data}

Notched bar creep test specimens with three different notch radii have been tested; $\mathrm{R}=1.88 \mathrm{~mm}$ (blunt), $\mathrm{R}=0.564 \mathrm{~mm}$ (medium) and $\mathrm{R}=0.188 \mathrm{~mm}$ (sharp), Fig. 2(b). Test conditions and some essential results are summarized in Table 1 with normalized experimental displacement-time curves reproduced in Fig. 5 for all tests. More detailed test results are given later, together with FE results using the simulation methods proposed in this study.

Table 1. Notched creep tensile test results.

\begin{tabular}{c|c|c|c|c}
\hline $\begin{array}{c}R \\
(\mathrm{~mm})\end{array}$ & ${ }^{1} \sigma_{\text {net }}(\mathrm{MPa})$ & Rupture time $(\mathrm{h})$ & ${ }^{2}\left(\varepsilon_{f}^{u}\right)_{\mathrm{EL}}(\%)$ & ${ }^{3}\left(\varepsilon_{f}^{u}\right)_{\mathrm{RA}}(\%)$ \\
\hline \hline \multirow{2}{*}{1.88} & 404 & 781 & 0.79 & 13.71 \\
\cline { 2 - 5 } & 423 & 686 & 0.84 & 16.08 \\
\hline \multirow{2}{*}{0.564} & 376 & 718 & 0.71 & 13.41 \\
\cline { 2 - 5 } & 414 & 322 & 0.81 & 13.58 \\
\hline \multirow{2}{*}{0.188} & 326 & 6164 & 0.63 & 10.56 \\
\cline { 2 - 5 } & 382 & 751 & 0.58 & 10.17 \\
\hline
\end{tabular}

${ }^{1} \sigma_{\text {net }}=P / A_{0}\left[1+2 \ln \left(d_{1} / d_{0}\right)\right] ; A_{0}$ is initial area; $d_{0}$ is initial notch diameter, $d_{1}$ is diameter after loading.

${ }^{2}$ uni-axial creep ductility based on elongation

${ }^{3}$ uni-axial creep ductility based on reduction of area, $\varepsilon_{f}^{u}=2 \ln \left(d_{\mathrm{f}} / d_{1}\right) ; d_{\mathrm{f}}$ is notch diameter at failure. 


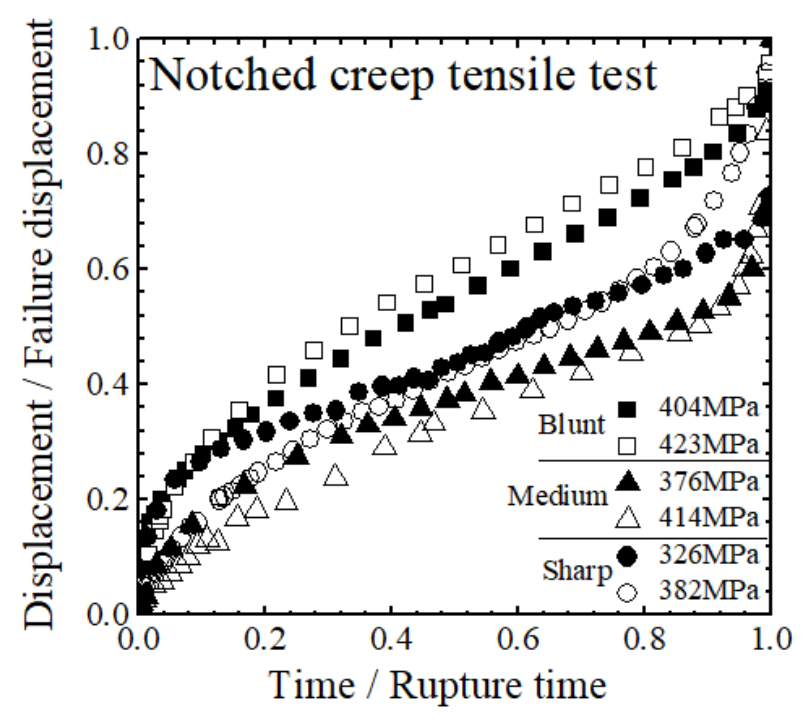

Fig. 5. Normalized experimental displacement-time curves for notched creep tensile tests. Further information on the tests is contained in Table 1.

\subsection{Creep Crack Growth Test Data}

Creep crack growth tests at $550{ }^{\circ} \mathrm{C}$ were performed using compact tension specimens without side grooves [19]. The width of the specimens was $W=26 \mathrm{~mm}$ and the thickness was $B$ $=13 \mathrm{~mm}$. Table 2 summarizes test conditions and durations. The magnitude of the applied sustained load $P$, is normalized with respect to the limit load $P_{0}$ given by [22]

$$
P_{0}=1.455\left\{\left[\left(\frac{2 a}{(\mathrm{~W}-a)}\right)^{2}+2\left(\frac{2 a}{\mathrm{~W}-a}\right)+2\right]^{1 / 2}-\left[\left(\frac{2 a}{\mathrm{~W}-a}\right)+1\right]\right\} B(\mathrm{~W}-a) \sigma_{0}
$$

where $a$ is the crack length and $\sigma_{0}$ is the yield stress. Values of $P / P_{0}$ for the initial crack size are also given in Table 2 and exceed unity, so that some plasticity is expected on initial loading. The values of $P / P_{0}$ increase during the tests, up to about 1.4 after a few millimetres crack growth, so that significant further plasticity occurs as the tests proceed. Experimental displacement-time and crack extension-time curves are shown in Fig. 6.

Table 2. Summary of creep crack growth tests on Type $316 \mathrm{H}$ at $550{ }^{\circ} \mathrm{C}$

\begin{tabular}{l|l|l|l|l}
\hline $\begin{array}{l}\text { Test } \\
\text { name }\end{array}$ & $P(\mathrm{kN})$ & $a / \mathrm{W}$ & $P / P_{0}$ & Test duration $(\mathrm{h})$ \\
\hline \hline CT1 & 10.72 & 0.45 & 1.24 & 120 \\
\hline CT2 & 8.98 & 0.45 & 1.05 & 1,312 \\
\hline
\end{tabular}




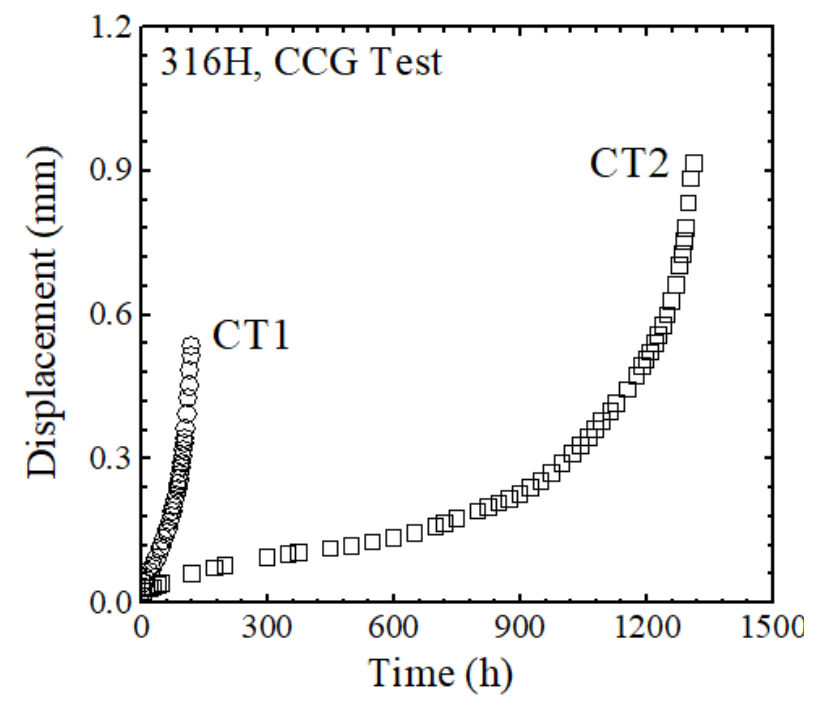

(a)

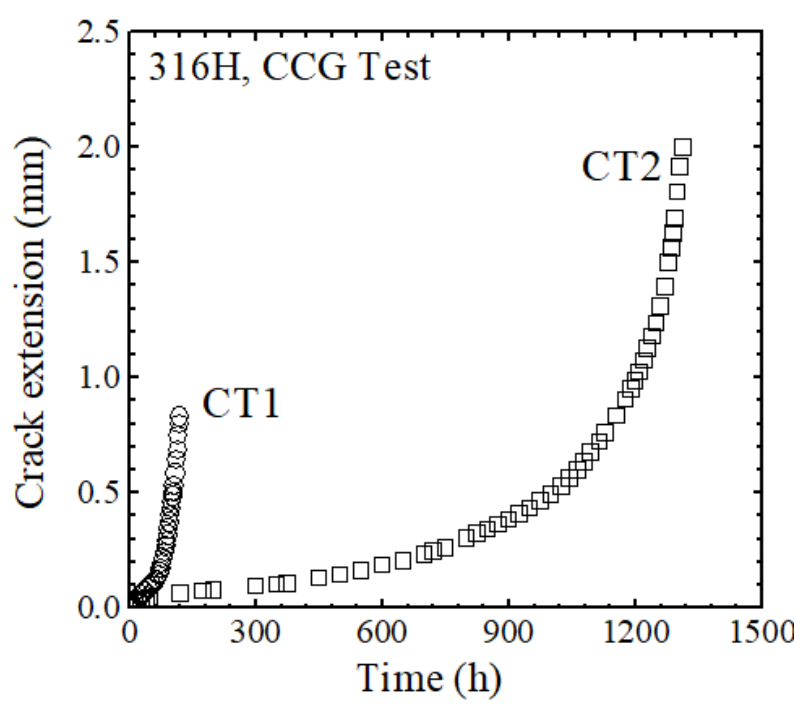

(b)

Fig. 6. (a) Experimental displacement-time curves and (b) crack extension-time curves from creep crack growth tests.

\section{COMBINED PLASTIC AND CREEP DAMAGE MODEL}

In most existing creep crack growth modelling, only creep damage is taken into account to simulate creep crack growth. However, in creep crack growth tests of creep ductile materials such as Type $316 \mathrm{H}$, creep crack growth can involve significant plasticity both on initial loading and as crack growth proceeds [19], as discussed in Section 2.5. Thus crack growth can occur not only due to creep but also due to plasticity and ductile tearing. Ainsworth and Booth [18] analysed crack growth in Type $316 \mathrm{H} \mathrm{C}(\mathrm{T})$ tests using a phenomenological model involving linear superposition of creep crack growth and ductile tearing described by $C^{*}$ and $J$, respectively. In this section, the interaction of creep and plasticity in crack growth is considered in more detail using a combined damage mechanics model, described in Section 3.1. A key input into damage models, for both plasticity and creep, is the influence of multiaxial stress. This is addressed in Section 3.2 for plasticity and in Section 3.3 for creep.

\subsection{The Proposed Combined Damage Model}

The combined damage model assumes that total crack growth is dependent on the linear superposition of creep and plastic damage [14]. Within the FE crack growth simulation, this is expressed as

$$
\Delta a=\left(\omega_{c r}+\omega_{p l}\right) L_{e}
$$


where $\omega_{c r}$ and $\omega_{p l}$ are the creep and plastic damage, respectively, and $L_{e}$ is a length parameter here taken as the FE element size. Eq. (4) may be considered to be the sum of tearing and creep crack growth

$$
\Delta a=\Delta a_{c r}+\Delta a_{p l}=\omega_{c r} L_{e}+\omega_{p l} L_{e}
$$

where $\Delta a_{c r}$ is the creep crack growth and $\Delta a_{p l}$ is the amount of ductile tearing. However, this separation is not strictly necessary within the model.

Incremental plastic damage $\Delta \omega_{p l}$ is defined by the ratio of the incremental plastic strain $\Delta \varepsilon_{p l}$ and the multi-axial plastic ductility $\varepsilon_{f},{ }^{*} p l$ :

$$
\Delta \omega_{p l}=\frac{\Delta \varepsilon_{p l}}{\varepsilon_{f, p l}^{*}}
$$

where $\varepsilon_{f},{ }^{*} p l$ is related to the uniaxial plastic ductility, $\varepsilon_{f, p l}^{u}$, by a multi-axial plastic ductility factor, $\mathrm{MDF}_{\mathrm{p}}$, defined by

$$
\varepsilon_{f, p l}^{*}=\varepsilon_{f, p l}^{u} \times M D F_{p}
$$

This is set out in more detail in Section 3.2. Incremental creep damage $\Delta \omega_{c r}$ is similarly defined by the ratio of the incremental creep strain $\Delta \varepsilon_{c r}$ and the multi-axial creep ductility $\varepsilon_{f, c r}{ }^{*}$, which in turn is a factor, $\mathrm{MDF}_{\mathrm{c}}$, times the uniaxial creep ductility, $\varepsilon_{f, c r}^{u}$. Hence,

$$
\Delta \omega_{c r}=\frac{\Delta \varepsilon_{c r}}{M D F_{c} \cdot \varepsilon_{f, c r}^{u}}
$$

The choice of $\mathrm{MDF}_{\mathrm{c}}$ is discussed in Section 3.3.

\subsection{Effect of Multiaxial Stress on Plastic Damage}

For plasticity, a modified Rice and Tracey model, successfully used previously to simulate ductile tearing [23-25], has been used to define the effect of multiaxial stress on plastic strain at failure. This is given by

$$
M D F_{p}=\alpha \exp \left(-1.5 \frac{\sigma_{m}}{\sigma_{e}}\right)+\beta
$$

where $\sigma_{m}$ is the mean stress; $\sigma_{e}$ is the equivalent stress and $\alpha, \beta$ are material constants. The ratio $\sigma_{m} / \sigma_{e}$ is termed the stress triaxiality. Note that the constants are chosen so that the value of $\mathrm{MDF}_{\mathrm{p}}$ is unity for the uniaxial tension test.

The two material constants, $\alpha$ and $\beta$, in Eq. (9) can be determined by comparing FE 
results with experimental tensile and toughness $(J-\mathrm{R})$ test results. This determination has been set out in previous work [23-25] and is briefly given here in Appendix. For the Type 316H material considered here, the final expression for $\mathrm{MDF}_{\mathrm{p}}$ is found to be

$$
M D F_{p}=1.609 \exp \left(-1.5 \frac{\sigma_{m}}{\sigma_{e}}\right)+0.162
$$

\subsection{Effect of Multiaxial Stress on Creep Damage}

Various forms of the multi-axial creep ductility factor, $\mathrm{MDF}_{\mathrm{c}}$, have been proposed; by Rice and Tracey (R\&T) [26], Cocks and Ashby (C\&A) [11], Wen and Tu (W\&T) [12] and Spindler (S) [27], for example. These models are not discussed in detail here but Cocks and Ashby proposed the following form:

$$
M D F_{c}=\sinh \left[\frac{2}{3}\left(\frac{n-0.5}{n+0.5}\right)\right] / \sinh \left[2\left(\frac{n-0.5}{n+0.5}\right) \frac{\sigma_{m}}{\sigma_{e}}\right]
$$

where $n$ is the stress exponent in power-law creep. Comparison of the models listed above shows that the Cocks and Ashby model gives the lowest $\mathrm{MDF}_{\mathrm{c}}$ value for a given stress triaxiality, with the Rice and Tracey model being much larger (more than $300 \%)$ at high triaxiality $\left(\sigma_{m} / \sigma_{e}\right.$ =3.0). This is illustrated in Fig. 7. Typical ranges of stress triaxiality for the notched bar and creep crack growth tests are shown in Fig. 7(b) to indicate the regions of importance.

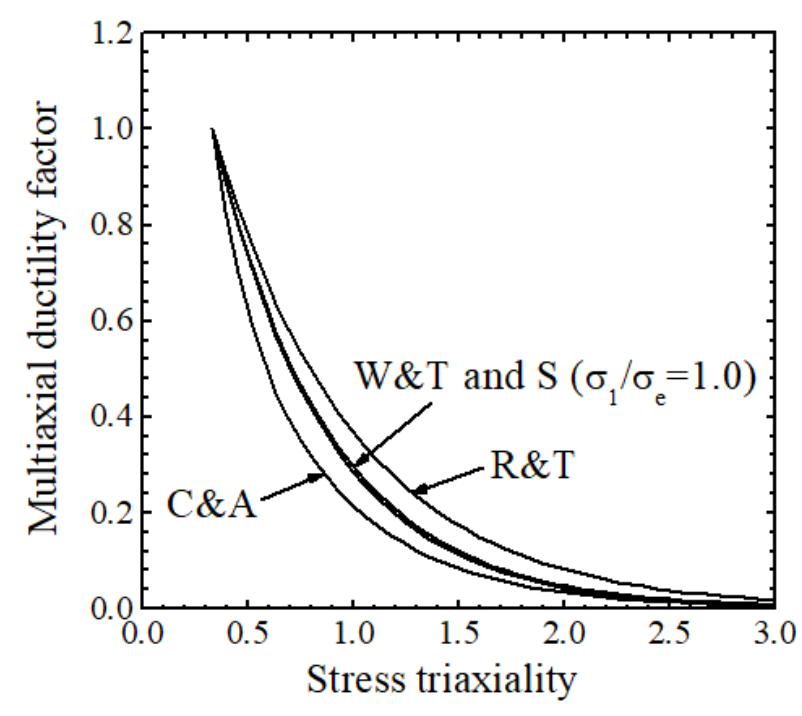

(a)

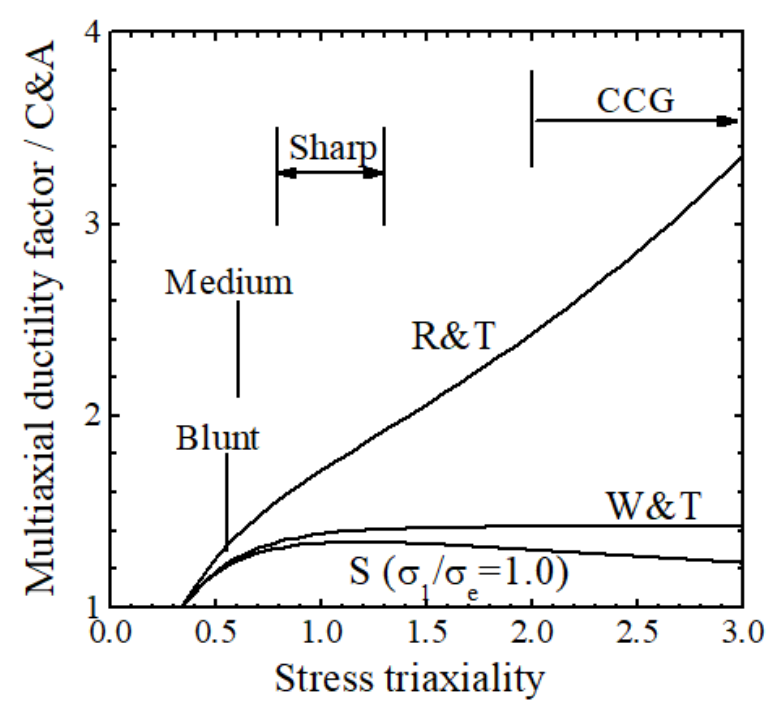

(b)

Fig. 7. (a) Comparison of various $\mathrm{MDF}_{\mathrm{c}}$ models in terms of the stress triaxiality, and (b) variations of normalized $\mathrm{MDF}_{\mathrm{c}}$ with respect to the Cocks and Ashby model with the stress triaxiality. 
The results of preliminary analyses discussed in Section 4 showed that the C\&A model predicted failure well in low stress triaxiality regimes but failure too early at higher stress triaxialities. This suggested that the $\mathrm{MDF}_{\mathrm{c}}$ values in the $\mathrm{C} \& \mathrm{~A}$ model, which at high stress triaxialities are lower than other models, are too low. Further, recognising that the $\mathrm{MDF}_{\mathrm{c}}$ values for all models approach zero as the stress triaxiality increases, which may not be realistic, a similar modification to that made to the Rice \& Tracey model in Eq. (9) has been made to the $\mathrm{C} \& \mathrm{~A}$ model by introducing a constant term, the minimum $\mathrm{MDF}_{\mathrm{c}}$ value $C$, leading to:

$$
M D F_{c}=(1-C) \times\left(\sinh \left[\frac{2}{3}\left(\frac{n-0.5}{n+0.5}\right)\right] / \sinh \left[2\left(\frac{n-0.5}{n+0.5}\right) \frac{\sigma_{m}}{\sigma_{e}}\right]\right)^{k}+C
$$

Note that a power exponent $k$ is also introduced in Eq. (12). This is chosen to make the modified model have almost the same values as the original C\&A model at low stress triaxialities, where the model had been found to work well.

Figure 8(a) shows Eq. (12) with three different values of $C(=0.0,0.014$ and 0.024$)$. The choice $C=0, k=1$ corresponds to the original C\&A model of Eq. (11). Normalized values of $\mathrm{MDF}_{\mathrm{c}}$ with respect to the original C\&A model are shown in Fig. 8(b). The choice of the value of $C$ is discussed further in Section 4.

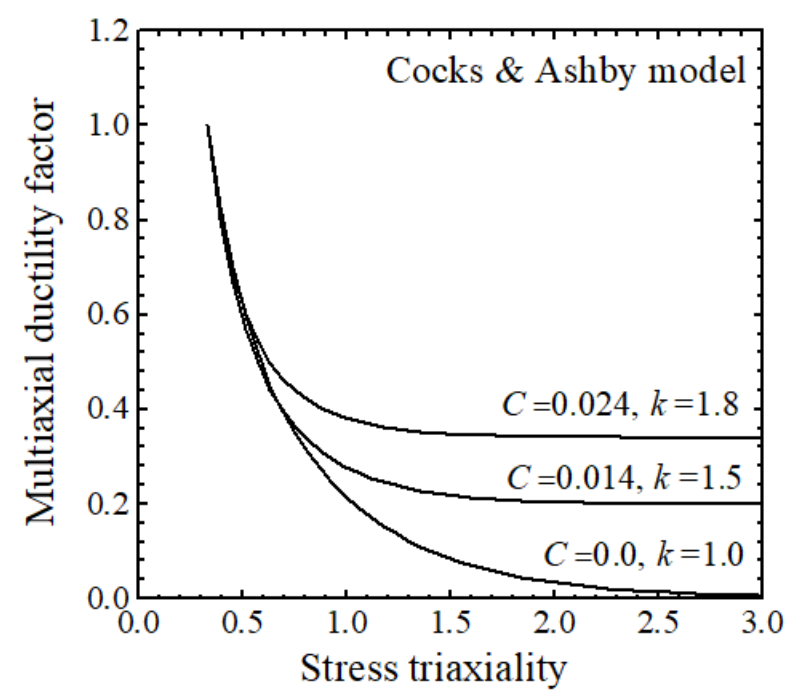

(a)

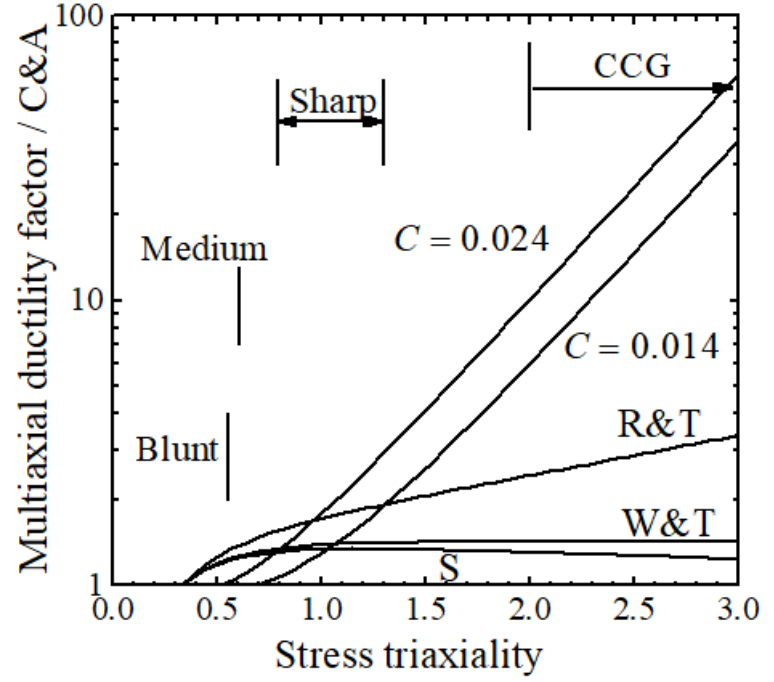

(b)

Fig. 8. (a) Comparison of the modified C\&A model with $C=0,0.014,0.024$ and (b) variations of $\mathrm{MDF}_{\mathrm{c}}$ normalized with respect to the original Cocks and Ashby model with the stress triaxiality.

\subsection{Strain Equations used in Simulations}


For the FE simulations, the true stress-strain data shown in Fig. 1 were directly used in the analysis to describe elastic-plastic response. For creep, the primary-secondary equations given in RCC-MRx A3 [28] for 316LN were used:

$$
\dot{\varepsilon}_{c r}^{p}=2.55 \times 10^{-27} \varepsilon_{c r}^{1.43} \sigma^{9.33}, \quad \dot{\varepsilon}_{c r}^{s}=8.97 \times 10^{-31} \sigma^{10.76}
$$

where $\dot{\varepsilon}_{c r}^{p}$ and $\dot{\varepsilon}_{c r}^{s}$ are primary and secondary creep strain rates, respectively. To simulate tertiary creep, the model proposed by Kachanov [29] was used:

$$
\dot{\varepsilon}_{c r}^{\omega}=\frac{\dot{\varepsilon}_{c r}^{s}}{\left[1-\left(\omega_{c r}^{\mathrm{s}}\right)\right]^{m}}, \quad \Delta \omega_{c r}^{s}=\frac{\Delta \varepsilon_{c r}^{s}}{\varepsilon_{f, c r}^{*}}
$$

where $\dot{\varepsilon}_{c r}^{\omega}$ is tertiary creep strain rate; $\omega_{c r}^{S}$ is damage due to secondary creep obtained from summation of incremental damage defined in the second part of Eq. (14) and $m$ is a material constant. By comparing the creep tensile test results and FE simulations of the plain creep specimens, a value of $m=2.6$ in Eq. (14) was chosen leading to the agreement shown in Fig. 3.

\section{DAMAGE SIMULATIONS}

\subsection{Basic Modelling Approach and FE Meshes}

Finite element creep simulations have been performed based on failure at a Gauss point occurring when the accumulated damage from summation of the increments of the damage terms of Eqs (6) and (8) becomes unity. Within the FE analysis, which were performed using ABAQUS [30], when the total damage was unity at a Gauss point, the elastic modulus was reduced to zero to simulate the loss of load-carrying capacity.

The notched bars were modelled using axisymmetric first-order elements with the FE mesh shown in Fig. 9(a) and the element size in the notch region fixed at $0.1 \mathrm{~mm}$ (similar to the grain size of Type $316 \mathrm{H}$ ). The creep crack growth tests simulations used three-dimensional firstorder solid elements. The 3-D FE mesh is shown in Fig. 9(b) and the element size in the crack growth region was again fixed at $0.1 \mathrm{~mm}$.

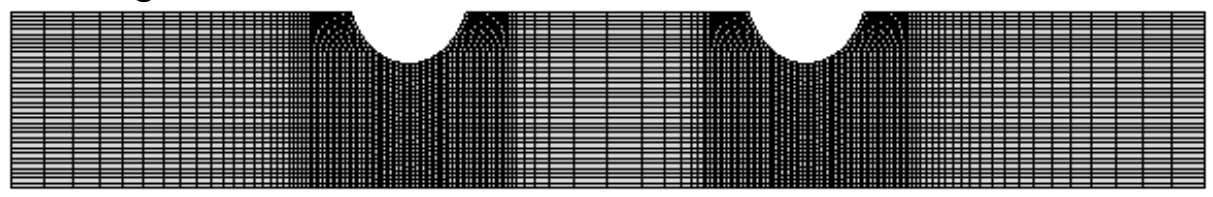




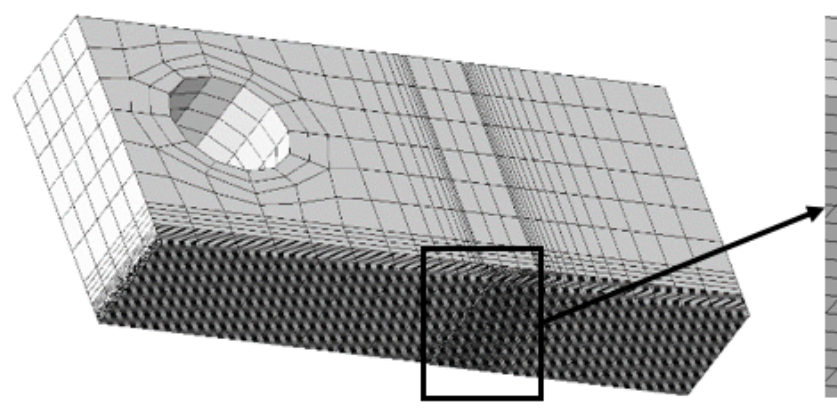

(a)

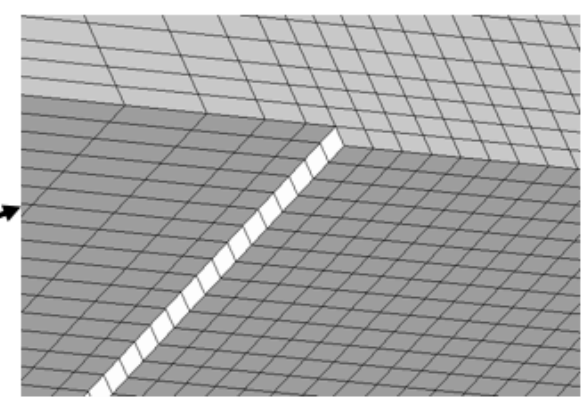

(b)

Fig. 9. Typical FE meshes to simulate: (a) notched bar creep tensile test and (b) creep crack growth test.

\subsection{Damage Analyses without Plastic Damage}

The notched bar and creep crack growth tests were initially simulated using various original multiaxial creep damage models without inclusion of plastic damage and with a fixed uniaxial ductility of 0.07 , i.e. without strain rate effects on ductility. For the blunt and medium notches, steady state creep deformation was relatively well predicted with all multiaxial models, but the predicted failure time depended on the multiaxial model. For the sharp notch, the simulation results depended more strongly on the choice of multiaxial model, with no model adequately describing both deformation and failure. Similar results were obtained from simulations of the creep crack growth tests. Again, the simulation results depended on the choice of multiaxial model, with no model adequately describing both deformation and failure.

Notched bar creep tensile tests were then re-analyzed using the modified C\&A model and the effect of $C$ on simulated results are shown in Fig. 10. For the blunt and medium notches, the effect of the value of $C$ on steady state creep deformation and failure time was not so significant but for the sharp notch, the simulations depended strongly on $C$, with creep cracking delayed as $C$ increased, as shown in Fig. 10. Creep crack growth simulations in the compact tension specimens were also performed using the modified C\&A model, and although the modified model led to an improved prediction of steady state deformation, this was still not satisfactory, and the simulations could not predict the tertiary response.

FE damage analyses including strain rate effects were then performed with the modified C\&A model with a value of the constant $C=0.024$ (which had given relatively good predictions for blunt notches). For the blunt and medium notch cases, incorporation of strain rate effects delayed failure prediction but only slightly. For the sharp notch case at the higher stress the FE simulations depended on inclusion of strain rate effects, because the creep strain rate for this case was in the transition region in Fig. 4. For the lower stress case, the FE simulations were not sensitive to the strain rate effect. 
Creep crack growth simulations of the $\mathrm{C}(\mathrm{T})$ test were also performed using the modified C\&A models with strain rate effects. Simulation results are compared with experimental data in Fig. 11. Simulations allowing for the effects of strain rate led to delayed crack initiation and improved predictions of steady state deformation for both tests (CT1 and CT2). However, crack growth in the tertiary part was still not predicted well.

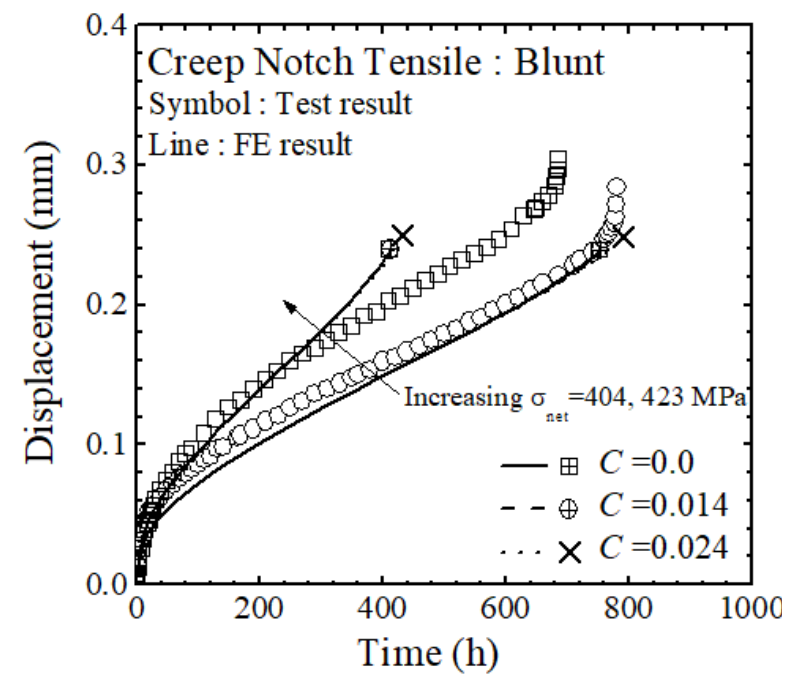

(a)

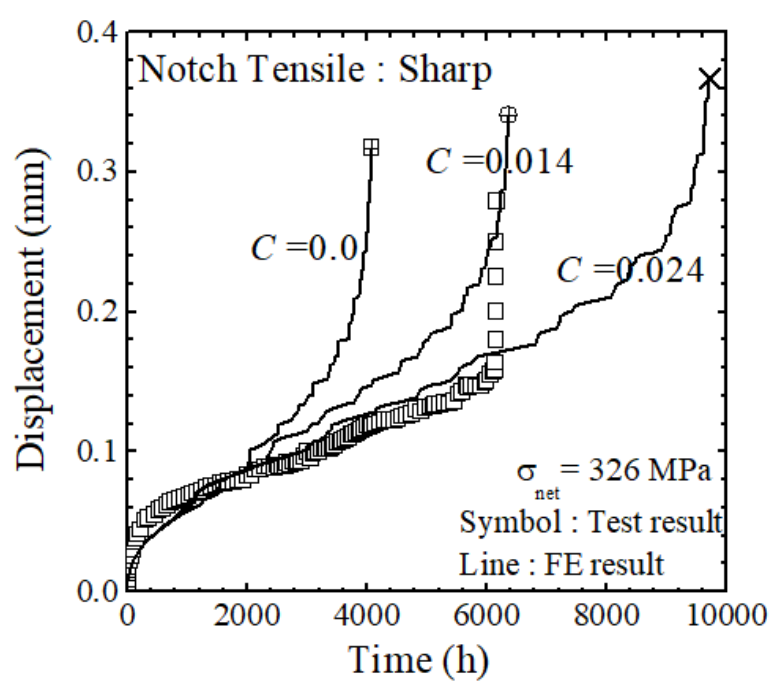

(b)

Fig. 10. Effect of $\mathrm{C}$ on simulation results for (a) blunt notch and (b) sharp notch.

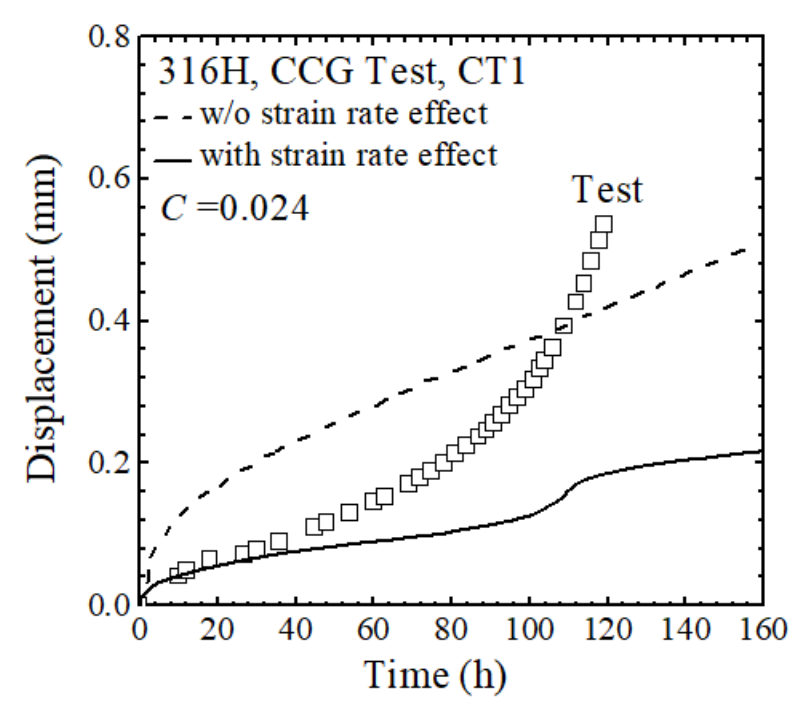

(a)

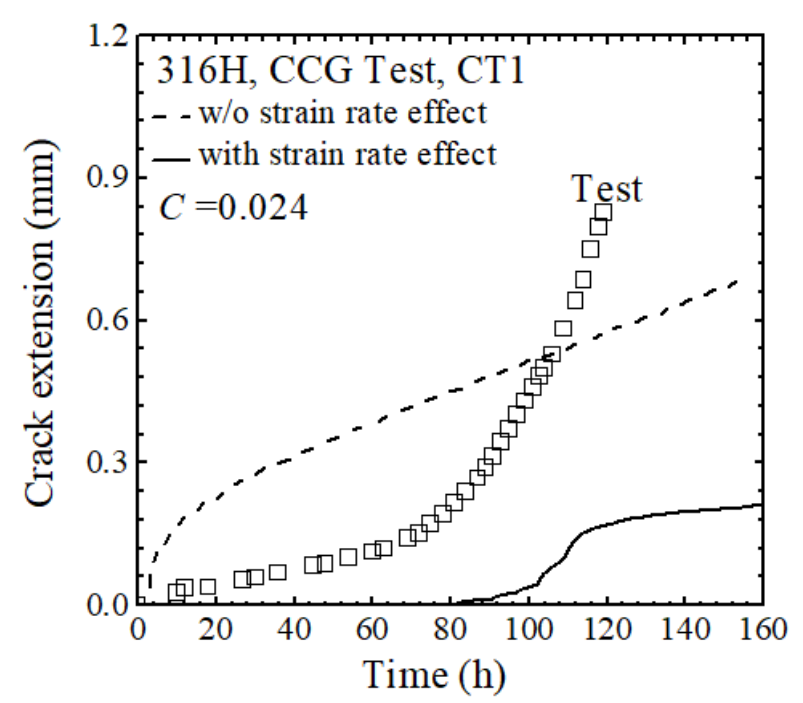

(b) 


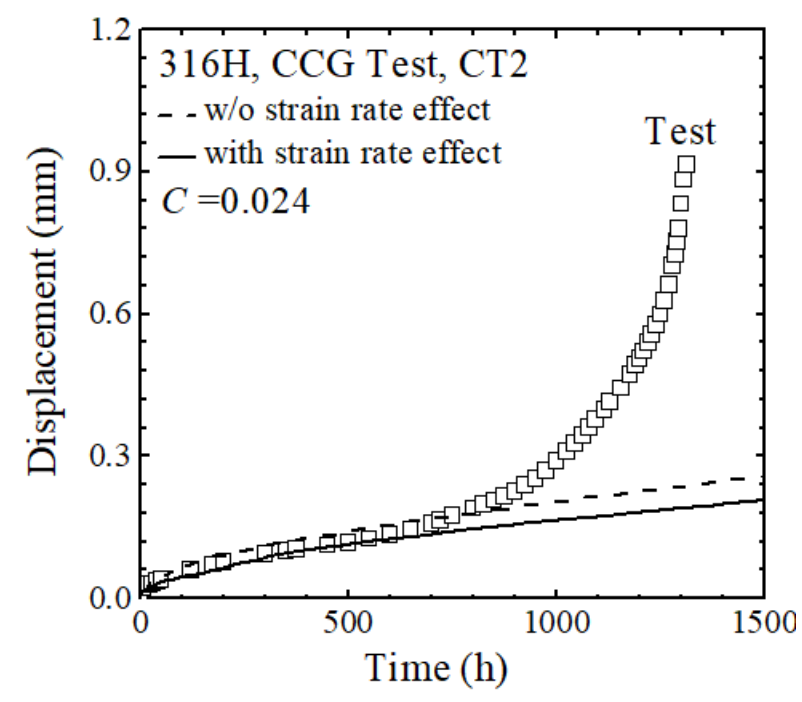

(c)

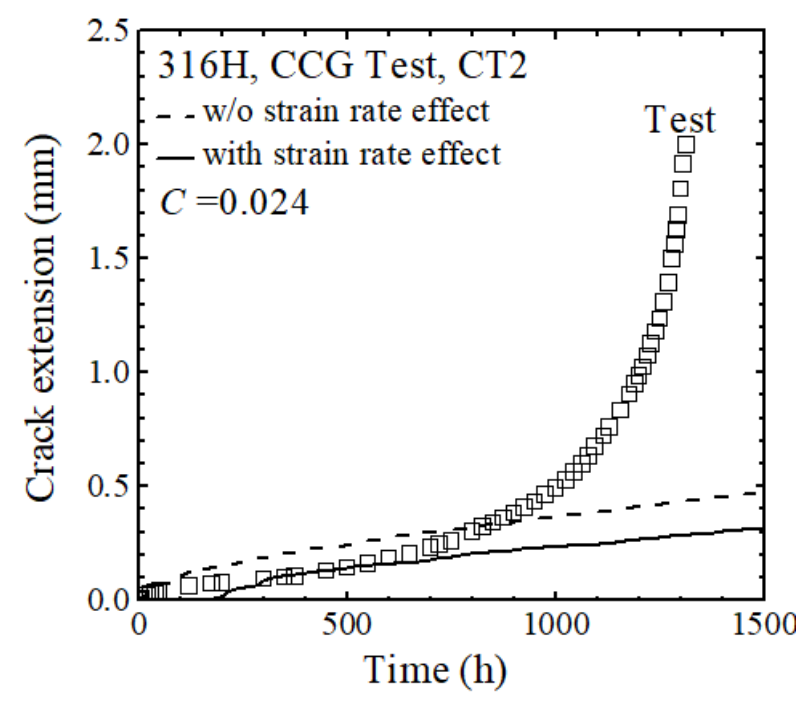

(d)

Fig. 11. FE simulation results without plastic damage and creep crack growth test data: (a)-(b) the CT1 test and (c)-(d) the CT2 test.

\subsection{Damage Analyses with Plastic Damage}

From comparison of the FE simulation results with experimental data of notched creep tensile and creep crack growth tests, as summarised briefly in Section 4.2, it was concluded that incorporation of strain rate effects leads to improved prediction of steady state deformation but is not sufficient to predict crack growth accurately. To resolve this, simulations incorporating plastic damage and therefore including the interaction of creep and plastic crack growth were performed and the results are reported in this section.

In the simulations, the creep and plastic damage terms are linearly added as described in Section 3.1 so that the total increment of damage at a Gauss point is

$$
\Delta \omega=\Delta \omega_{c r}+\Delta \omega_{p l}=\frac{\Delta \varepsilon_{c r}}{\varepsilon_{f, c r}^{*}}+\frac{1}{1.7}\left[\frac{\Delta \varepsilon_{p l}}{\varepsilon_{f, p l}^{*}}\right]=\frac{\Delta \varepsilon_{c r}}{\varepsilon_{f, c r}^{u} \cdot M D F_{c}}+\frac{1}{1.7}\left[\frac{\Delta \varepsilon_{p l}}{\varepsilon_{f, p l}^{u} \cdot M D F_{p}}\right]
$$

Note that the factor of 1.7 in the plastic damage calculation is a correction factor to scale plastic and creep damage for the chosen element size. More detailed explanation is given in Appendix. When accumulated incremental total damage becomes unity, the elastic modulus was reduced to zero to simulate the loss of the load-carrying capacity as described in Section 4.1.

The FE simulation results for notched bar creep tensile tests are compared with experimental data in Fig. 12. In all cases, addition of the plastic damage provides earlier failure prediction and simulation results using the combined plastic and creep damage model agree well with experimental data. Although not shown, the effect of adding plastic damage does not affect 
smooth bar creep test simulation results. In Figs. 12(a) and 12(b), addition of plastic damage affects only failure time. This is because for blunt and medium notch cases, failure occurs just after crack initiation in simulation. Plastic damage does not have effect on displacement until crack initiation.

Creep crack growth simulations in the $\mathrm{C}(\mathrm{T})$ tests were also performed using the combined damage model. Simulation results are compared with experimental displacementtime and crack extension-time data in Fig. 13. It can be seen that addition of plastic damage leads to significantly improved crack growth predictions compared to simulations without plastic damage.

Figure 14 shows variations of the stress triaxiality in the crack tip region with distance from the growing crack tip. In both creep crack growth tests, the maximum stress triaxiality at the crack tip tends to increase as the crack grows. Corresponding variations of the strain rate in the crack tip region with distance from the growing crack tip are shown in Fig. 15. The plastic strain rate tends to increase slightly as the crack grows, but the creep strain rate tends to decrease. The plastic strain rate in the CT1 test case is around $10^{-2} \mathrm{~h}^{-1}$ which corresponds to the upper shelf region of the strain rate, see Fig. $4 \mathrm{~b}$. In the CT2 test, the creep and plastic strain rates are lower than those in the CT1 test and correspond to the lower shelf region. Figure 16 shows variations of the accumulated damage at the crack tip region. For the CT1 test, a significant amount of plastic damage is accumulated during initial loading. For the CT2 test, a smaller amount of plastic damage is accumulated during initial loading, compared to the CT1 test. The overall tendency is that, as the crack grows, the plastic damage increases and thus the creep damage portion decreases. Calculated normalized damage for creep and plastic as a function of the crack growth amount is shown in Fig. 17. During the initial part of the crack growth, the creep damage is dominant, but the plastic damage becomes more dominant as the crack grows. This confirms the need to model both plasticity and creep damage during the later parts of the tests.
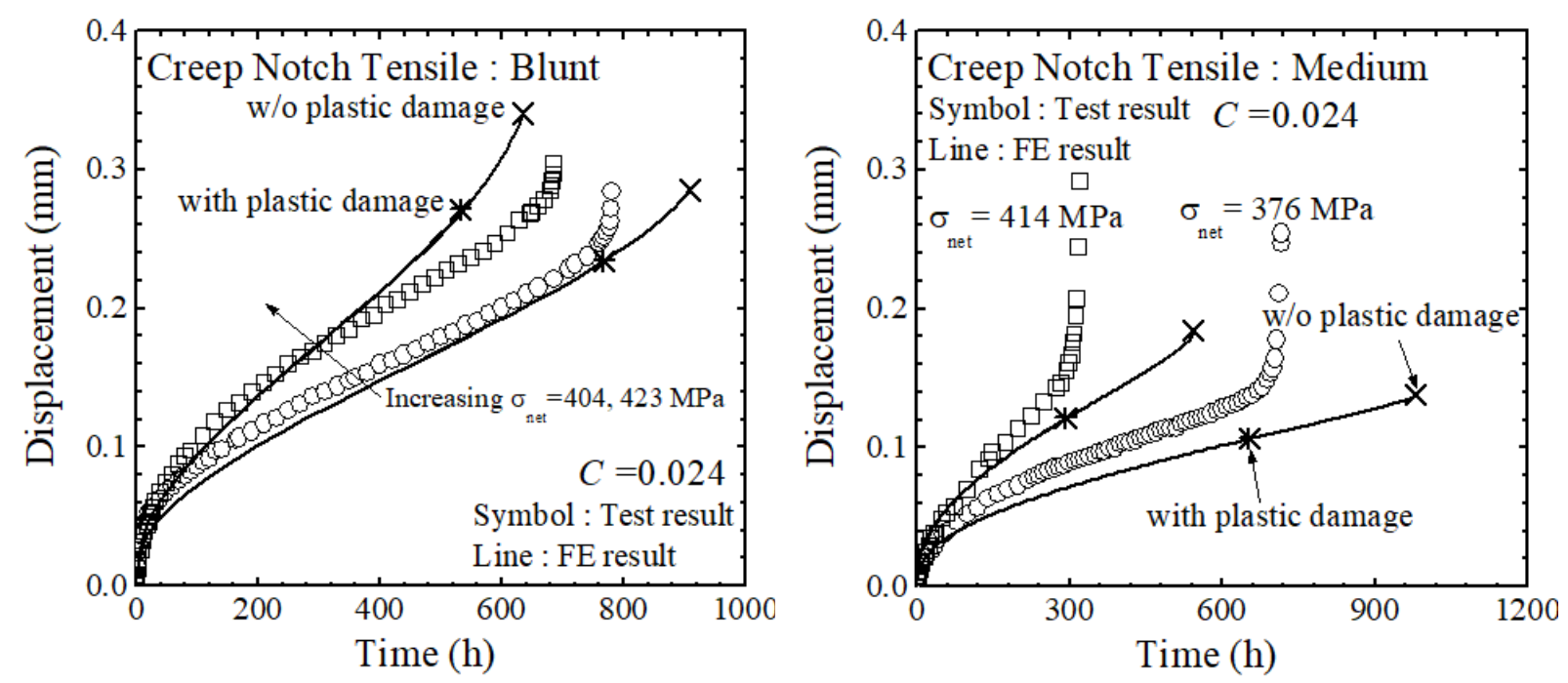
(a)

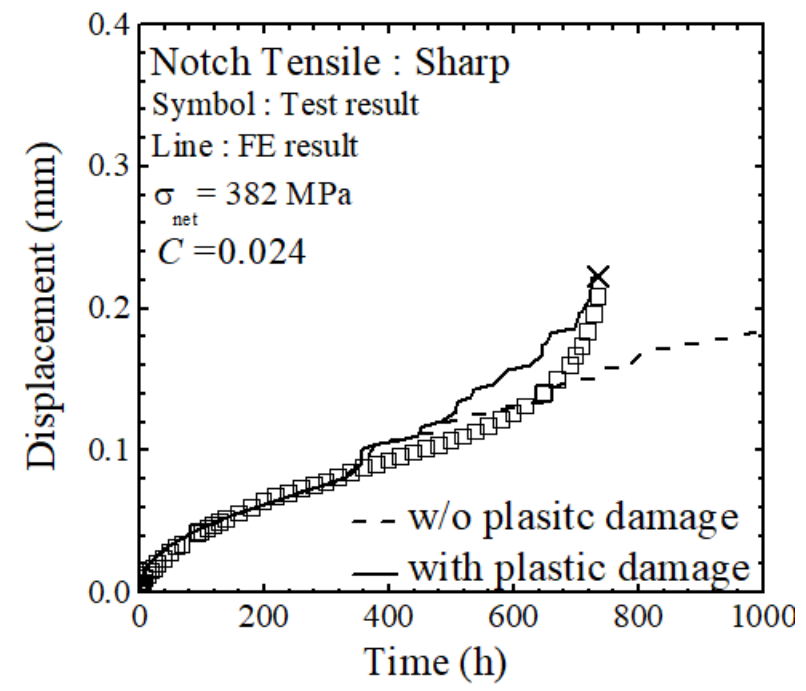

(c) (b)

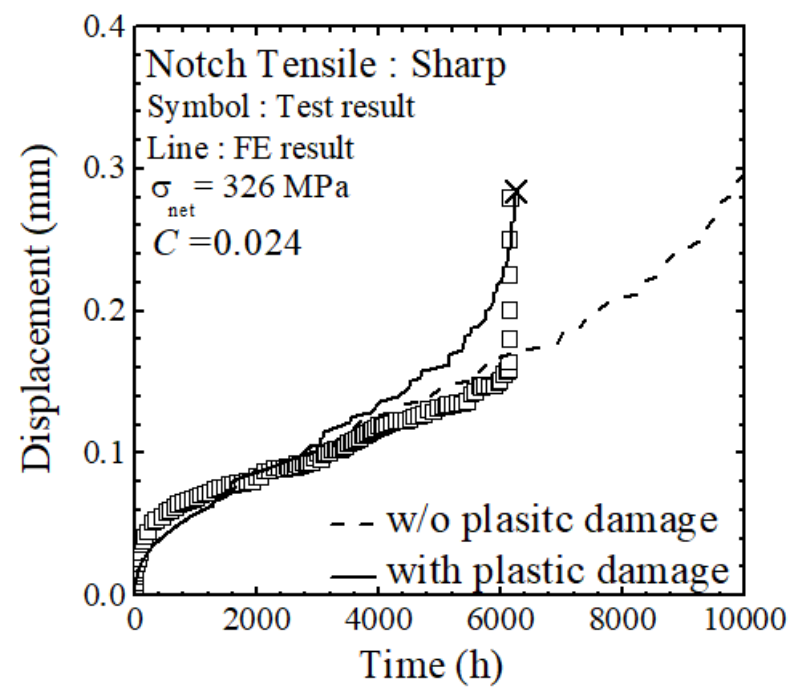

(d)

Fig. 12. Comparison of FE simulation results with notched bar creep tensile test data: (a) the blunt case, (b) the medium case, (c) the sharp case for $\sigma_{\text {net }}=382 \mathrm{MPa}$ and (d) the sharp case for $\sigma_{\text {net }}=326 \mathrm{MPa}$.

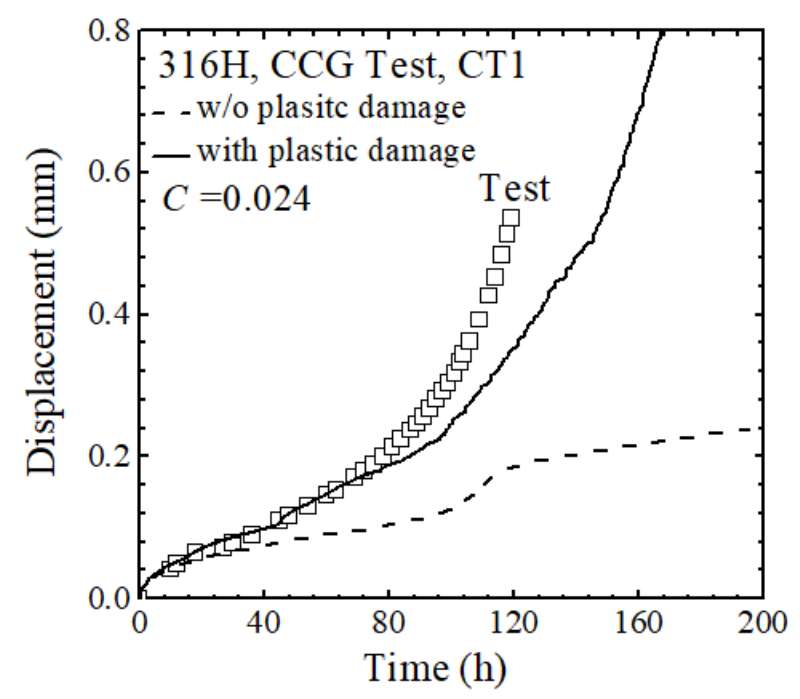

(a)

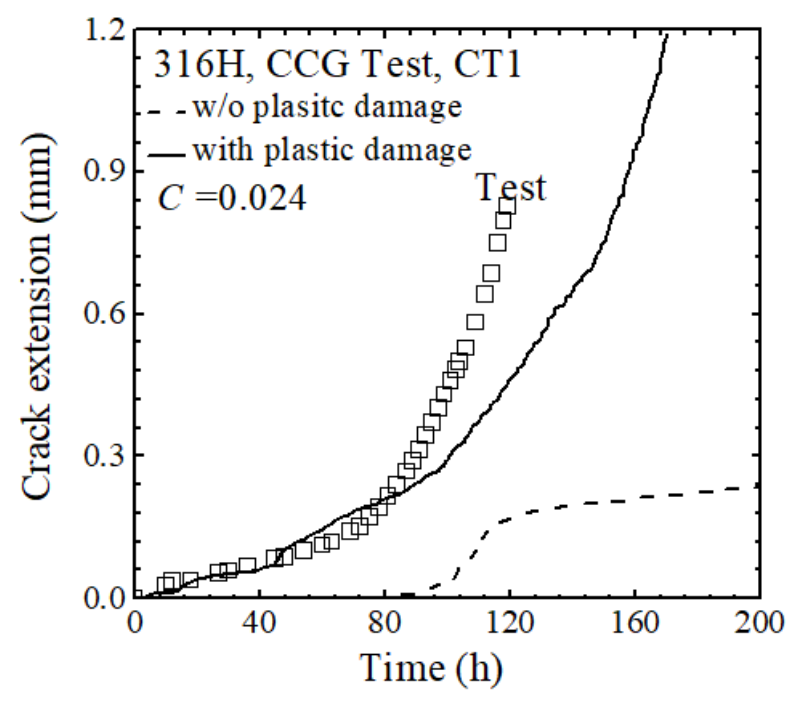

(b) 


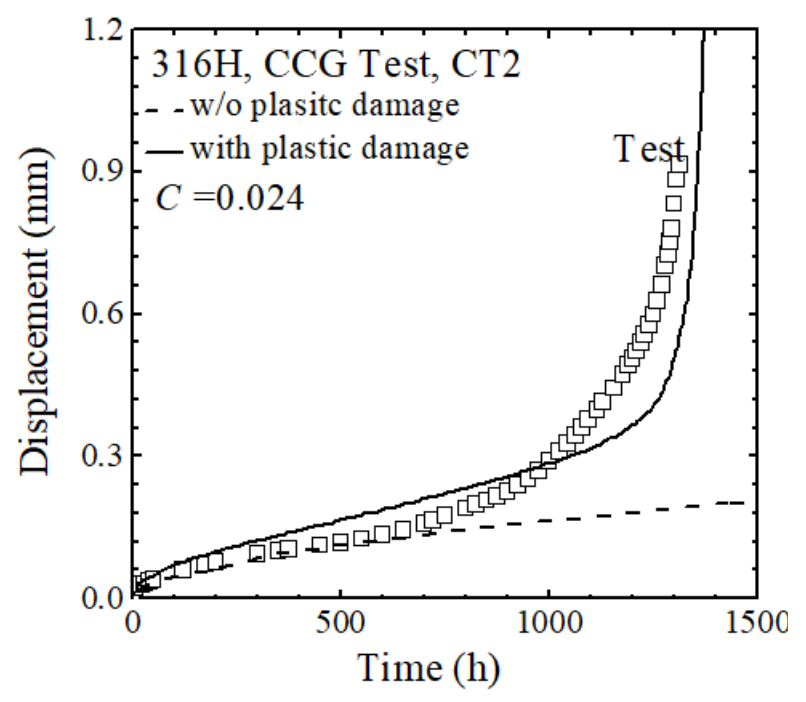

(c)

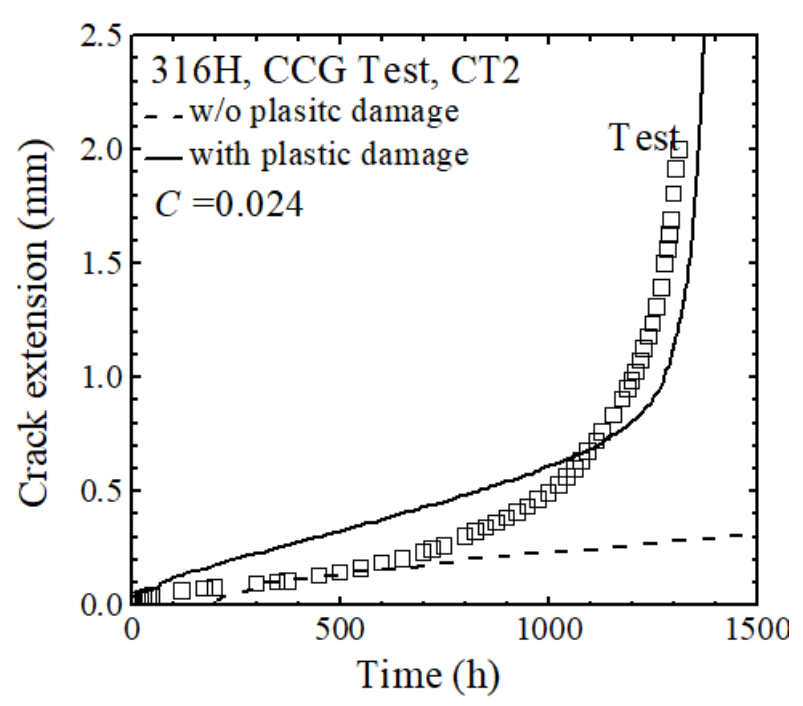

(d)

Fig. 13. Comparison of FE simulation results with creep crack growth test data: (a)-(b) the CT1 test and (c)-(d) the CT2 test.

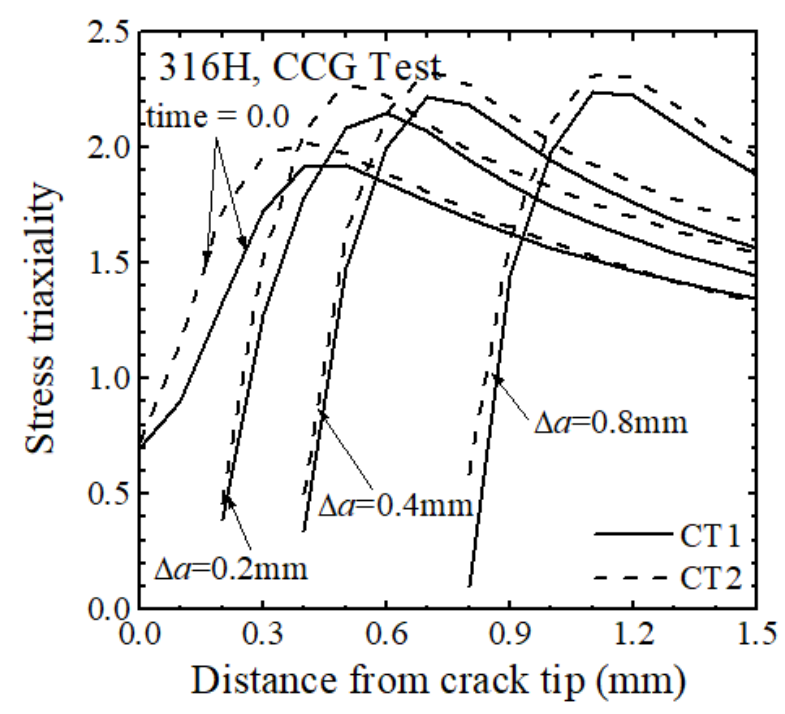

Fig. 14. Variation of the stress triaxiality at the crack tip region with the distance from the growing crack tip. 


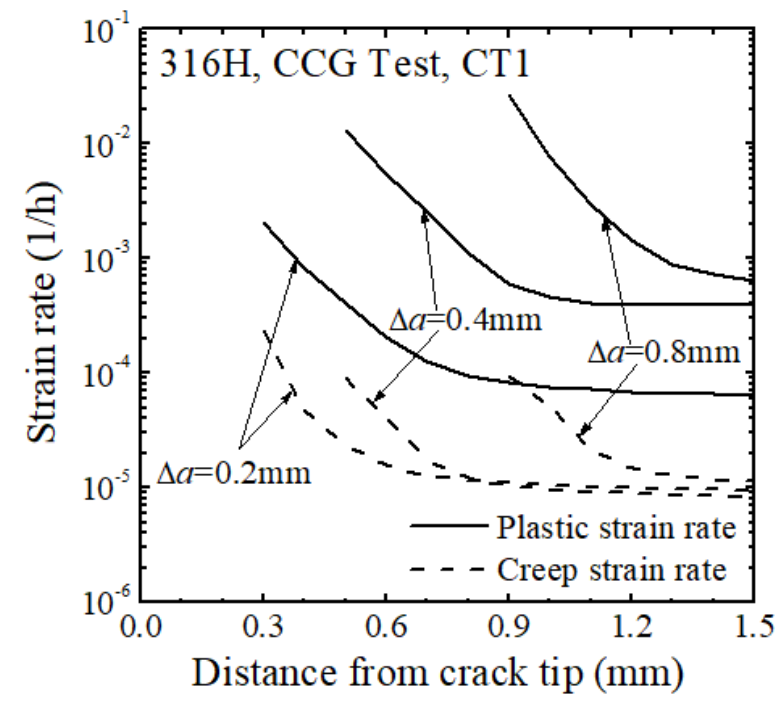

(a)

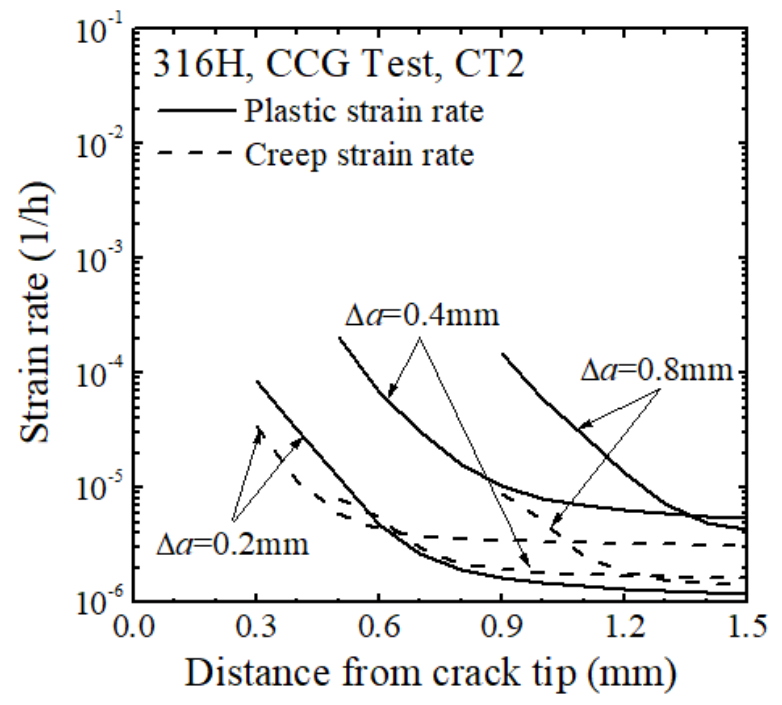

(b)

Fig. 15. Variation of the strain rate at the crack tip region with the distance from the growing crack tip: (a) the CT1 test and (b) the CT2 test.

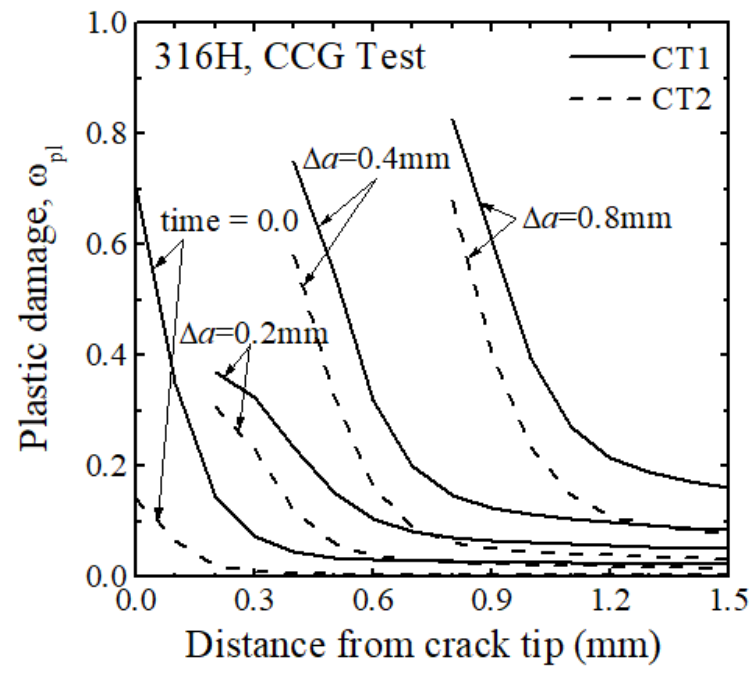

(a)

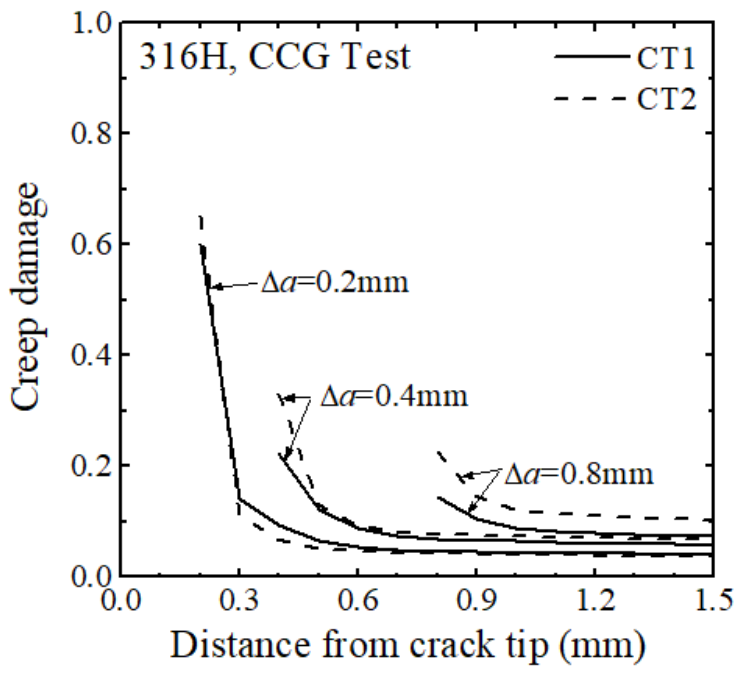

(b)

Fig. 16. Variation of the accumulated damage at the crack tip region with the distance from the growing crack tip: (a) the plastic damage and (b) the creep damage. 


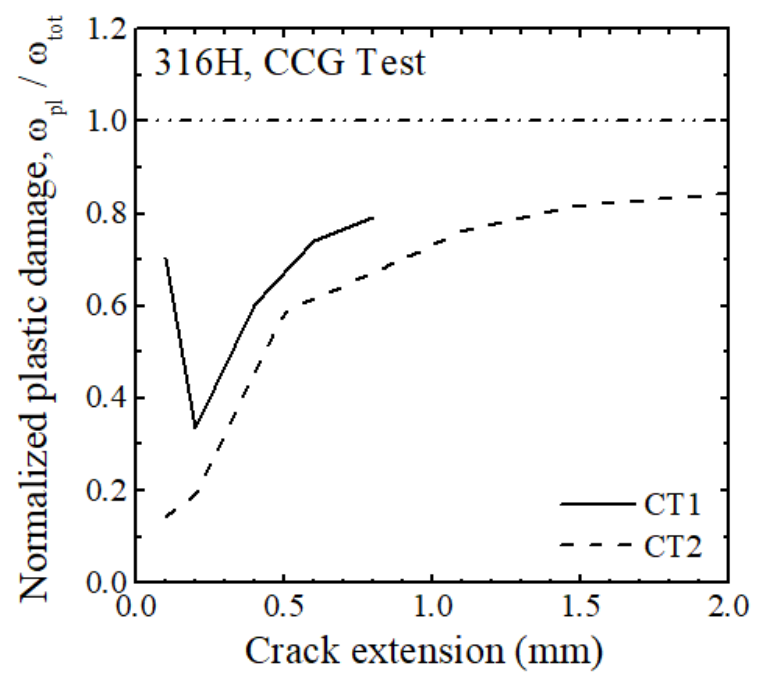

(a)

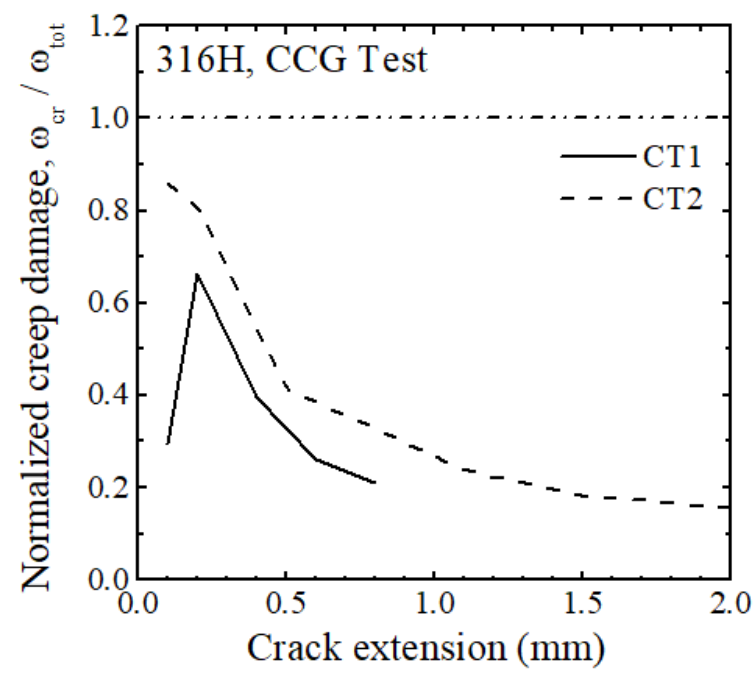

(b)

Fig. 17. Accumulated damage with crack extension: (a) normalized plastic damage and (b) normalized creep damage.

\section{CONCLUDING REMARKS}

In this paper, a numerical model has been proposed to simulate the interaction of ductile tearing and creep crack growth in a cracked component. A strain-based combined creep and plastic damage model has been introduced and incremental creep and plastic damage have been defined using strain-rate-dependent multi-axial ductility models. The concept of the combined damage model is that total crack growth is assumed to be the linear superposition of ductile tearing and creep crack growth. The combined damage model has been refined to address three issues: the effect of a multi-axial ductility factor on creep crack growth simulation; the effect of the strain rate on ductility; and the effect of plastic damage on creep crack growth simulation.

It has been found that conventional multi-axial creep ductility models tend to predict earlier failure than observed in high stress triaxiality regimes. To resolve this, a modified C\&A model with a minimum ductility at high stress triaxiality has been introduced. From comparison of FE simulation results with experimental data, it has been found that the modification leads to improved failure predictions for notched bar creep tests but without allowing for other issues still gives poor predictions of steady state crack growth in creep crack growth simulations. Introduction of the strain-rate-dependent uni-axial ductility and the combined creep and plastic damage model has been found to lead to simulation results, which agree well with all creep experimental data. 


\section{APPENDIX: DETERMINATION OF MULTI-AXIAL DUCTILITY FACTOR FOR PLASTICITY}

To determine the two constants, $\alpha$ and $\beta$, in Eq. (9), FE analyses were performed to simulate tensile and fracture toughness tests under monotonic loading. Axi-symmetric, elasticplastic FE analysis (without using the damage model) was performed to simulate smooth bar tensile test. The FE mesh is shown in Fig. A.1(a). The first order solid elements (CAX4 within ABAQUS [30]) were used with an element size of $0.1 \mathrm{~mm}$. The true stress-strain curve shown in Fig. 1 was used in the FE analysis. To incorporate large deformation in tensile testing, the large geometry change option was used with the $J_{2}$ flow theory. A deformed FE mesh after necking is shown in Fig. A.1(b). Local stress and strain values in the centre of the specimen were extracted from the FE results and variations of the stress triaxiality with the equivalent plastic strain, extracted from the centre of the specimen, are shown in Fig. A.2(a) as a solid line. Results show that the stress triaxiality in the centre of the specimen depends on the equivalent plastic strain. The stress triaxiality increases with increasing equivalent plastic strain after necking. To include the history of stress and strain, the stress triaxiality over the loading history is averaged, and the resulting averaged value of the stress triaxiality is shown in Fig. A.2(a) by a dotted line. This stress triaxiality value corresponds to the uni-axial tensile ductility and thus to the point where the $\mathrm{MDF}_{\mathrm{p}}$ equals unity, as schematically shown in Fig. A.2(b). To determine Eq. (9) completely, however, we need one more point in Fig. A.2(b) and this is done by comparing an experimental $J$-R curve [31] with simulation results using FE damage analyses, as described below.

To simulate ductile crack growth in a C(T) test, 3-D FE damage analyses were performed, using the technique proposed by the authors [23-25]. In the 3-D FE model, eight-noded brick elements with full integration (C3D8 within ABAQUS) of $0.1 \mathrm{~mm}$ element size were uniformly spaced in the crack propagation region. The FE mesh is shown in Fig. A.1(c). To incorporate large deformation in the simulation, the large (nonlinear) geometry change option was chosen. To determine one more constant in Eq. (9), several $\mathrm{MDF}_{\mathrm{p}}$ expressions were postulated by assuming a value at high stress triaxiality of $\sigma_{m} / \sigma_{e}=2.5$. As schematically illustrated in Fig. A.2(b), for instance, the $\mathrm{MDF}_{\mathrm{p}}$ values of $0.1,0.2$ and 0.3 were assumed at $\sigma_{m} / \sigma_{e}=2.5$ (referred to as the Case 1, Case 2 and Case 3, respectively).

In FE calculations, incremental plastic damage is calculated using

$$
\Delta \omega_{p l}=\frac{\Delta \varepsilon_{p l}}{\varepsilon_{f, p l}^{*}} \quad \text { with } \quad \varepsilon_{f, p l}^{*}=0.867 \cdot M D F_{p}
$$

where 0.867 corresponds to the uni-axial tensile ductility. Local failure is assumed when the accumulated damage (at a FE Gauss point) becomes the critical value, $\omega_{p l}=\sum \Delta \omega_{p l}=\omega_{c}$. Ductile tearing simulation results will be affected by the critical plastic damage $\omega_{c}$. 
In Fig. A.3(a), variations of tearing modulus $(\Delta J / \Delta a)$ with $\Delta a$, measured from the experimental $J$-R curve, are compared with simulated results with different assumed $\mathrm{MDF}_{\mathrm{p}}$ functions (three cases). Results suggest that simulated tearing modulus depends strongly on the choice of $\mathrm{MDF}_{\mathrm{p}}$. Results using $\mathrm{MDF}_{\mathrm{p}}=0.2$ at $\sigma_{m} / \sigma_{e}=2.5$ (Case 2) agree well with experimental data, suggesting that $\mathrm{MDF}_{\mathrm{p}}$ for $316 \mathrm{H}$ at $550{ }^{\circ} \mathrm{C}$ is given by

$$
M D F_{p}=\left[1.609 \exp \left(-1.5 \frac{\sigma_{m}}{\sigma_{e}}\right)+0.162\right]
$$

The effect of the critical damage on simulated $J$-R curves using $\mathrm{MDF}_{\mathrm{p}}$ from Eq. (A.2) is shown in Fig. A.3(b). This shows that the simulated $J$-R curves are significantly affected by the critical plastic damage and a proper critical plastic damage for ductile tearing simulations of $316 \mathrm{H}$ at $550{ }^{\circ} \mathrm{C}$ is found to be $\omega_{c}=1.7$.

In FE simulations using the combined creep and plastic damage model, both creep and plastic damage values are linearly added. Local failure by creep crack growth occurs when $\omega_{c r}$ $=\sum \Delta \omega_{c r}=1$. On the other hand, local failure by ductile tearing occurs when $\omega_{p l}=\sum \Delta \omega_{p l}=\omega_{c}$. For scaling creep and plastic damage, an increment of damage is then calculated using the following equation with the correction factor

$$
\Delta \omega=\Delta \omega_{c r}+\Delta \omega_{p l}=\frac{\Delta \varepsilon_{c r}}{\varepsilon_{f, c r}^{*}}+\frac{1}{\omega_{c}}\left[\frac{\Delta \varepsilon_{p l}}{\varepsilon_{f, p l}^{*}}\right]=\frac{\Delta \varepsilon_{c r}}{\varepsilon_{f, c r}^{*}}+\frac{1}{1.7}\left[\frac{\Delta \varepsilon_{p l}}{\varepsilon_{f, p l}^{*}}\right]
$$

When accumulated incremental total damage becomes unity, the elastic modulus was reduced to zero to simulate the loss of the load-carrying capacity

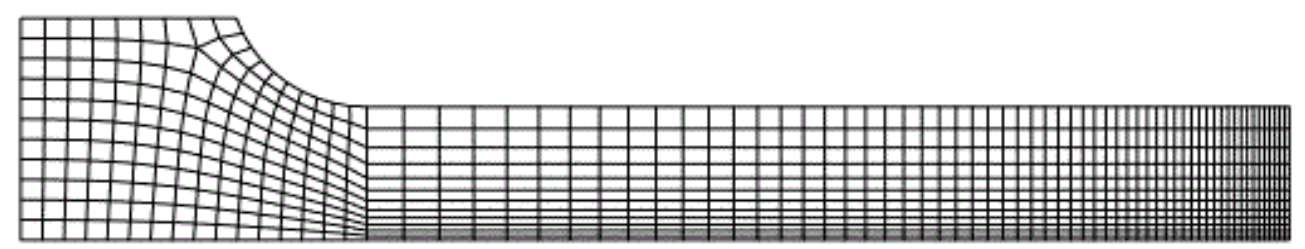

(a)

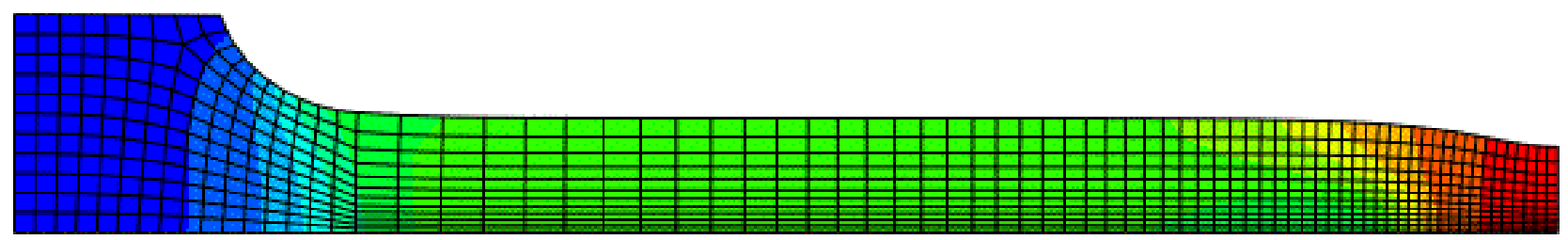

(b) 


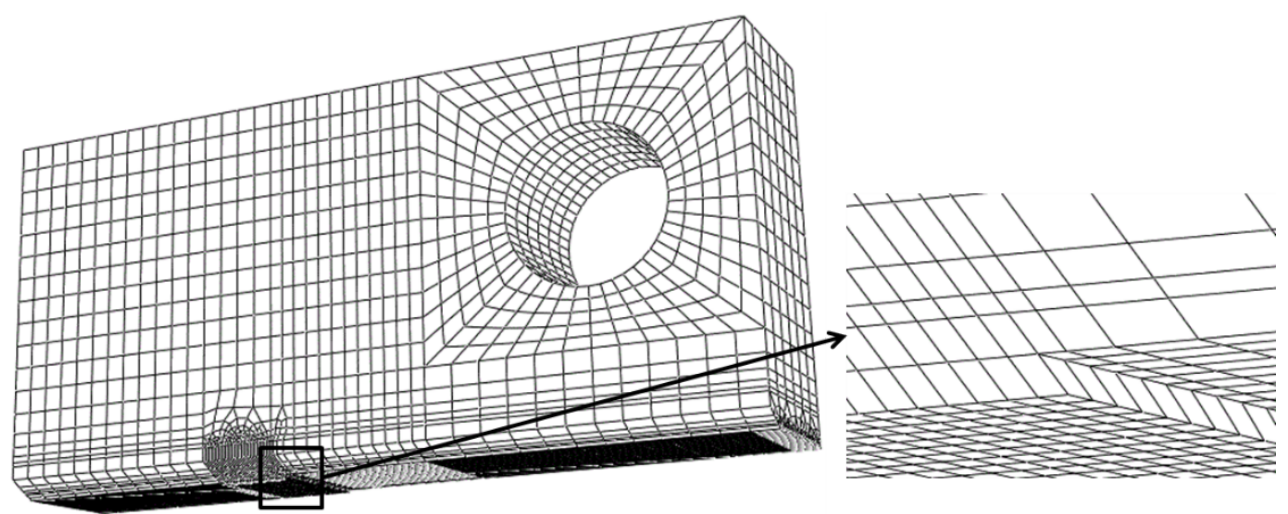

(c)

Fig. A.1. (a) FE mesh to simulate tensile test, (b) deformed mesh after necking, and (c) typical FE mesh to simulate ductile tearing of the $\mathrm{C}(\mathrm{T})$ specimen.

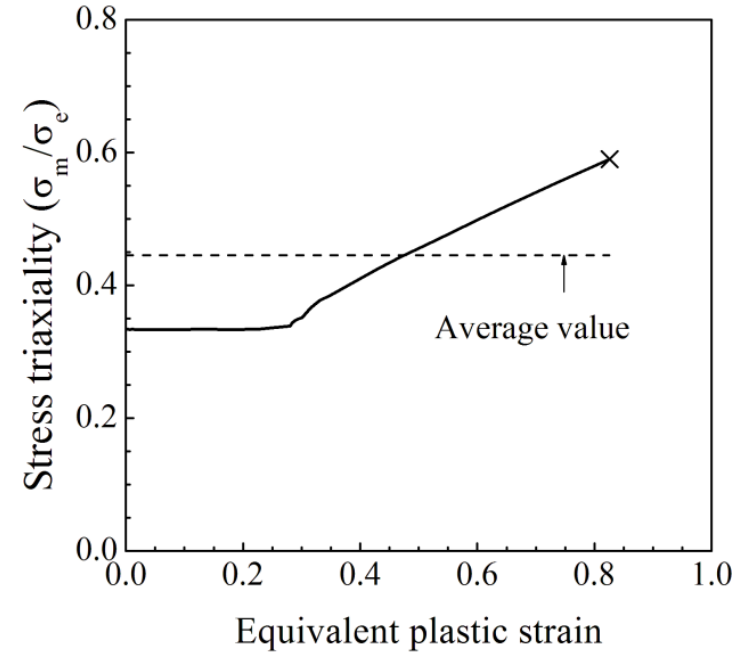

(a)

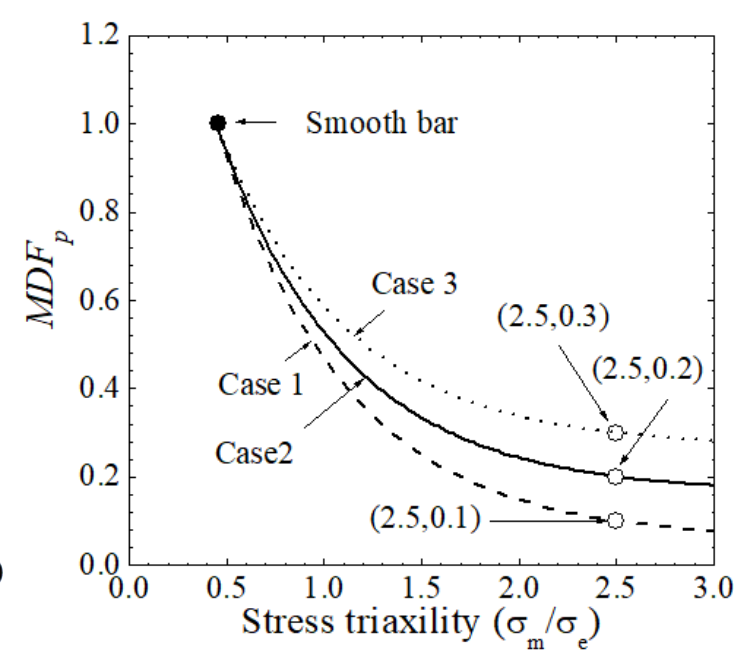

(b)

Fig. A.2. (a) Variations of the stress triaxiality with equivalent plastic strain for smooth tensile test and (b) three different assumed $\mathrm{MDF}_{\mathrm{p}}$ functions for plastic damage calculations.
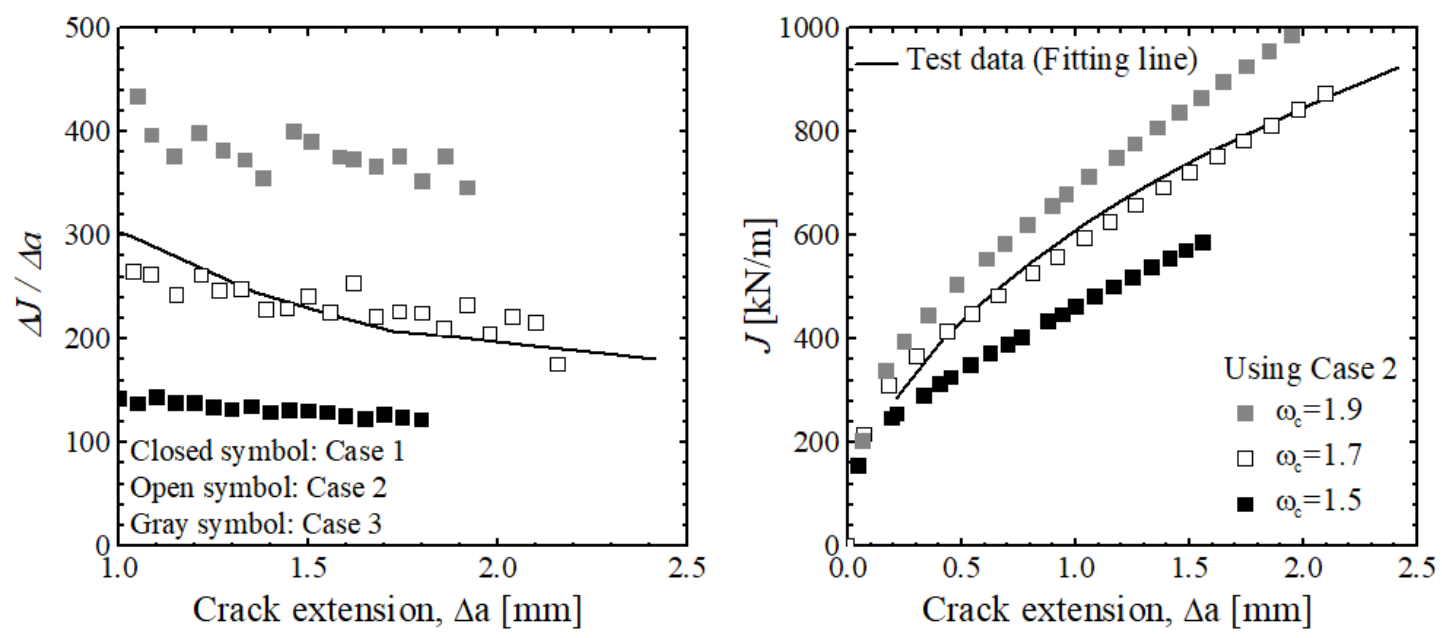
Fig. A.3. (a) Effects of $M D F_{p}$ on simulated tearing moduli and (b) effect of the critical damage, $\omega_{c}$, on simulated $J$-R curves.

\section{ACKNOWLEDGEMENT}

This research was supported by National Research Foundation of Korea (NRF) funded by the Ministry of Science, ICT and Future Planning. (NRF-2013M2B2B1075733 and NRF2017R1A2B2009759)

\section{REFERENCES}

[1] Hall FR, Hayhurst DR. Continuum damage mechanics modelling of high temperature deformation and failure in a pipe weldment. Proc R Soc Lond, A 1991;433:383-403.

[2] Hayhurst DR. Creep rupture under multi-axial states of stress. J Mech Phys Solids 1972;20:381-90.

[3] Hayhurst DR, Dimmer PR, Morrison CJ. Development of continuum damage in the creep rupture of notched bars. Phil Trans R Soc A 1984;311:103-29.

[4] Hayhurst DR, Brown PR, Morrison CJ. The role of continuum damage in creep crack growth. Phil Trans R Soc A 1984;311:131-58.

[5] Perrin IJ, Hayhurst DR. Continuum damage mechanics analyses of type IV creep failure in ferritic steel cross-weld specimens. Int J Pres Ves Piping 1999;76:599-617.

[6] Hyde TH, Sun W, Becker AA. Creep crack growth in welds: a damage mechanics approach to predicting initiation and growth of circumferential cracks. Int J Pres Ves Piping 2001;78:765-71.

[7] Yatomi M. Factors affecting the failure of cracked components at elevated temperature. Ph.D. Thesis. Department of Mechanical Engineering, Imperial College London;2003.

[8] Yatomi M, Nikbin KM, O'Dowd NP. Creep crack growth prediction using a damage based approach. Int J Pres Ves Piping 2003;80:573-83.

[9] Yatomi M, Nikbin KM, O'Dowd NP. Theoretical and numerical modelling of creep crack growth in a carbon-manganese steel. Int J Pres Ves Piping 2006;73:573-83.

[10] Yatomi M, Davies CM, Nikbin KM. Creep crack growth simulations in $316 \mathrm{H}$ stainless steel. Engng Fract Mech 2008;75:5140-50.

[11] Cocks ACF, Ashby MF. Intergranular fracture during power-law creep under multiaxial stresses. Metal Science 1980;14.

[12] Wen JF, Tu ST, Xuan FZ, Zhang XW, Gao XL. Effects of stress level and stress state on creep ductility: Evaluation of different models. J Mat Sci Tech 2016;32;695-704.

[13] Wen JF, Tu ST, Gao XL, Reddy JN. Simulations of creep crack growth in 316 stainless steel using a novel creep-damage model. Engng Fract Mech 2013;98:169-84.

[14] Wen JF, Tu ST, Gao XL, Reddy JN. New model for creep damage analysis and its application to creep crack growth simulations. Mat Sci Tech 2014;30:32-37.

[15] Wen JF, Tu ST. A multiaxial creep-damage model for creep crack growth considering cavity growth and microcrack interaction. Engng Fract Mech 2014;123:197-210.

[16] Oh CS, Kim NH, Kim YJ, Davies C, Nikbin K, Dean D. Creep failure simulations of 
$316 \mathrm{H}$ at $550^{\circ} \mathrm{C}$ : part 1-a method and validation. Engng Fract Mech 2011;78:2966-77.

[17] Kim NH, Oh CS, Kim YJ, Davies C, Nikbin K, Dean D. Creep failure simulations of $316 \mathrm{H}$ at $550^{\circ} \mathrm{C}$ : Part II - effects of specimen geometry and loading mode. Engng Fract Mech 2013;105:169-181

[18] Ainsworth RA, Booth SE. The interaction of ductile tearing and creep crack growth. Strength, Fract \& Complexity: Int J 2015;8:43-59.

[19] Bettinson AD. The influence of constraint on the creep crack growth of $316 \mathrm{H}$ stainless steel. $\mathrm{PhD}$ thesis. Department of Mechanical Engineering, Imperial College London 2010.

[20] CRETE. Development and harmonisation of creep crack growth testing for industrial specimens - a route to a European code of practice EU framework 5 project, GRD22000-30021;2001-2004.

[21] Spindler MW. The development of improved methods for the calculation of creep damage in Type 316H steel. E/REP/BDB/0023/AGR/03, Rev.000. British Energy;2003.

[22] Kumar V, German MD, Shih CF. Engineering approach for elastic-plastic fracture analysis. Electric Power Research Institute (Report) EPRI NP. 1981.

[23] Oh CS, Kim NH, Kim YJ, Baek JH, Kim YP, Kim WS. A finite element ductile failure simulation method using stress-modified fracture strain model. Engng Fract Mech 2011;78:124-137.

[24] Kim NH, Oh CS, Kim YJ, Yoon KB, Ma YH. Comparison of fracture strain based ductile failure simulation with experimental results. Int J Pres Ves Piping 2011;88:43447.

[25] Kim JH, Kim NH, Kim YJ, Hasegawa K, Miyazaki K. Ductile fracture simulation of 304 stainless steel pipes wuth two circumferential surfave cracks. Fatigue Fract Engng Mater Struct 2013;36:1967-80.

[26] Rice JR. On the ductile enlargement of voids in triaxial stress fields. J Mech Phys Solids 1969;17:201-217.

[27] Spindler MW. The multiaxial creep ductility of austenitic stainless steels. Fatigue Fract Engng Mater Struct 2004;27:273-281.

[28] RCC-MRx code A3. AFCEN;2010.

[29] Kachanov LM. Introduction to continuum damage mechanics. Kluwer Academic Publisher 1986

[30] ABAQUS, Version 6.13: User's manual. Inc. and Dassault Systemes;2013.

[31] Davies CM. Crack initiation and growth at elevated temperatures in engineering steels. $\mathrm{PhD}$ thesis. Department of Mechanical Engineering, Imperial College London 2006. 